\title{
Role of predation by harp seals Pagophilus groenlandicus in the collapse and non-recovery of northern Gulf of St. Lawrence cod Gadus morhua
}

\author{
Emmanuel Chassot ${ }^{1,4, *}$, Daniel Duplisea ${ }^{1}$, Mike Hammill ${ }^{1}$, Amanda Caskenette ${ }^{1}$, \\ Nicolas Bousquet ${ }^{2}$, Yvan Lambert ${ }^{1}$, Garry Stenson ${ }^{3}$ \\ ${ }^{1}$ Fisheries and Oceans Canada, Institut Maurice-Lamontagne, 850 route de la Mer, Mont-Joli, Quebec, G5H 3Z4, Canada \\ ${ }^{2}$ Département de Mathématiques et Statistiques, Université Laval, Pavillon Alexandre-Vachon, Quebec, G1K 7P4, Canada \\ ${ }^{3}$ Fisheries and Oceans Canada, Northwest Atlantic Fisheries Centre, PO Box 5667, St. John's, Newfoundland, A1C 5X1, Canada
}

${ }^{4}$ Present address: IRD, CRH, Avenue Jean Monnet, BP 171, 34203 Sète Cedex, France

\begin{abstract}
A statistical catch-at-age model was developed to assess the effects of predation by the northwest Atlantic harp seal population on northern Gulf of St. Lawrence cod by estimating the relative importance of different sources of mortality that affected the stock during a period of collapse and non-recovery. Cod recruitment at age 1 is modeled via a non-linear stock-recruitment relationship based on total egg production and accounts for changes in female length-at-maturity and cod condition. Natural mortality other than seal predation also depends on cod condition used as an integrative index of changes in environmental conditions. The linkage between seals and cod is modeled through a multi-age functional response that was derived from the reconstruction of the seal diet using morphometric relationships and stomach contents of more than 200 seals collected between 1998 and 2001. The model was fitted following a maximum likelihood estimation approach to a scientific survey abundance index (1984 to 2006). Model results show that the collapse of the northern Gulf of St. Lawrence cod stock was mainly due to the combination of high fishing mortality rates and poor environmental conditions in the early to mid-1990s contributing to the current state of recruitment overfishing. The increase in harp seal abundance during 1984 to 2006 was reflected by an increase in predation mortality for the young cod age-groups targeted by seals. Although current levels of predation mortality affect cod spawning biomass, the lack of recovery of the NGSL cod stock seems mainly due to the very poor recruitment.
\end{abstract}

KEY WORDS: Cod $\cdot$ Harp seal $\cdot$ Functional response $\cdot$ Model $\cdot$ Predation $\cdot$ Recovery

Resale or republication not permitted without written consent of the publisher

\section{INTRODUCTION}

During the early 1990s, there was an almost simultaneous collapse among most of the Atlantic cod Gadus morhua L. fisheries in eastern Canada, leading to severe restrictions or moratoria on commercial fishing (Myers et al. 1997, Rice et al. 2003). The northern Gulf of St. Lawrence (NGSL) cod stock (NAFO divisions 3Pn4RS; Fig. 1) was historically the second largest cod population in the Western Atlantic with a spawning stock biomass (SSB) of $380000 \mathrm{t}$ in the early 1980s, sup- porting a fishery of more than $100000 \mathrm{t}$ in 1983 (MPO 2007). By the late 1980s, the population and fishery declined to such an extent that a moratorium was imposed in 1994, leaving a SSB of only about $10000 \mathrm{t}$. Subsequently, the population increased quite rapidly and in 1997, a small fishery reopened, although the stock has remained at about $50 \%$ of its minimum conservation biomass limit $\left(B_{\lim }\right)$ of about 80000 to $90000 \mathrm{t}$.

There has been considerable debate concerning the causes for the decline in cod abundance and subsequent lack of recovery (Hutchings 1996, Shelton \& 


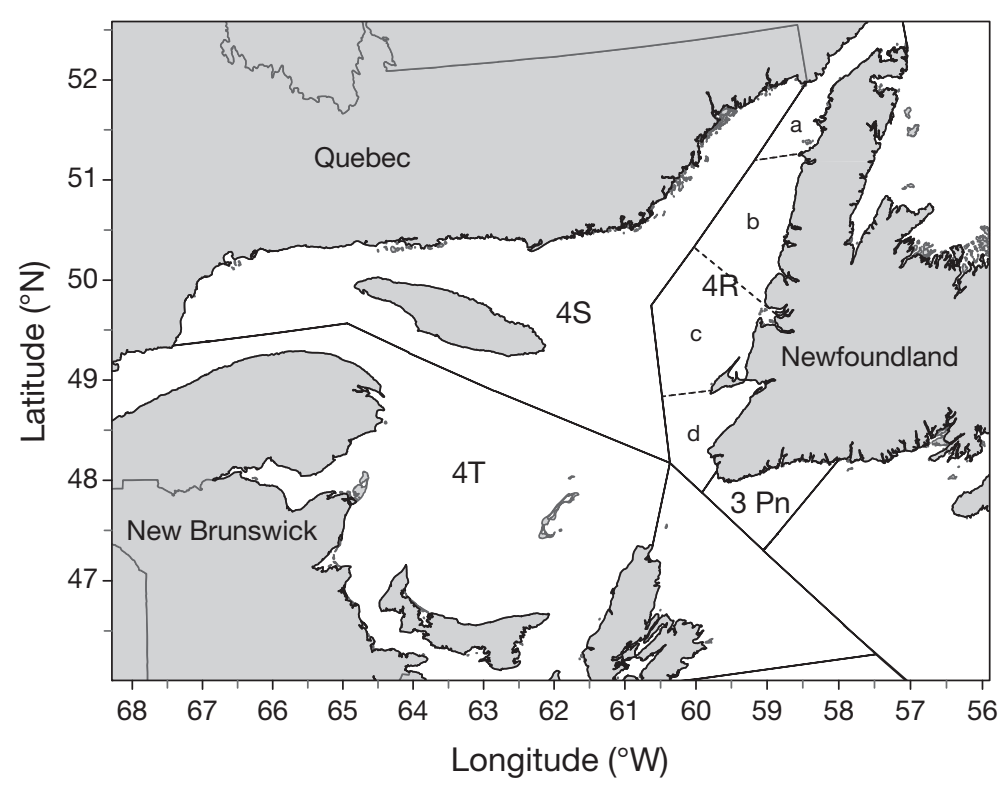

Fig. 1. Northern Gulf of St. Lawrence (NAFO divisions 4R and 4S)

land and in the NGSL (Fig. 2). The majority of the seals overwinter off the southeastern Labrador-northeastern Newfoundland coast (NAFO Divisions 2J3KL), while approximately 25 to $33 \%$ of the harp seals move into the NGSL (Stenson et al. 2002, 2003). Harp seals are generalist predators characterized by a diverse diet of fish and invertebrates (e.g. Lawson et al. 1998, Hammill \& Stenson 2000). Stomach samples collected during the winter and spring in the NGSL indicate that their diet is highly variable, both seasonally and geographically, with an average of approximately $5 \%$ made up by cod mainly in the size range of 15 to $25 \mathrm{~cm}$. In some samples, this proportion may be as high as $45 \%$ (Hammill \& Stenson 2004, Stenson \& Hammill 2004).

The correspondence between the decline of NGSL cod and the large increase in harp seal abundance (Fig. 3) has led to the

Healey 1999, Shelton et al. 2006). Overfishing has been identified as the main factor contributing to the collapse due to several interrelated common factors, including underestimated discarding and misreporting (Myers et al. 1996, Myers et al. 1997, Savenkoff et al. 2004). For the NGSL cod stock, it has been suggested that changes in environmental conditions in the early 1990s also played a role in the fishery collapse through a decline in cod condition, which consequently resulted in reduced growth and recruitment (Lambert \& Dutil 1997a, Dutil et al. 1999, Dutil \& Lambert 2000). Poor condition is also suspected to have led to an increase in natural mortality through starvation and enhanced vulnerability to predation (Dutil et al. 1999). The current poor productivity of the stock, combined with ongoing fishing activity, has been proposed as a major factor explaining the lack of recovery for NGSL cod (Dutil et al. 2003, Shelton et al. 2006).

During the last 3 decades, there has been a marked increase in abundance of many pinniped populations in the northwest Atlantic (Hammill et al. 1998, Hammill \& Stenson 2005). Higher natural mortality of northwest Atlantic groundfish resulting from increased predation by seals has also been put forward as a plausible hypothesis explaining the collapse and failure of populations to recover (Bundy 2001, DFO 2003, Rice et al. 2003). In particular, harp seals Pagophilus groenlandicus, the most abundant pinniped in the northwest Atlantic, have increased from less than 2 million individuals in the early 1970s to almost 6 million today (Hammill \& Stenson 2005). Harp seals summer in the Arctic, but migrate south along the Labrador coast in late autumn to overwinter off northeastern Newfoundhypothesis that harp seal predation may play a significant role in the lack of cod population recovery (McLaren et al. 2001, DFO 2003). Seal predation on cod has been examined using bioenergetic models that derive annual consumption estimates by taking into

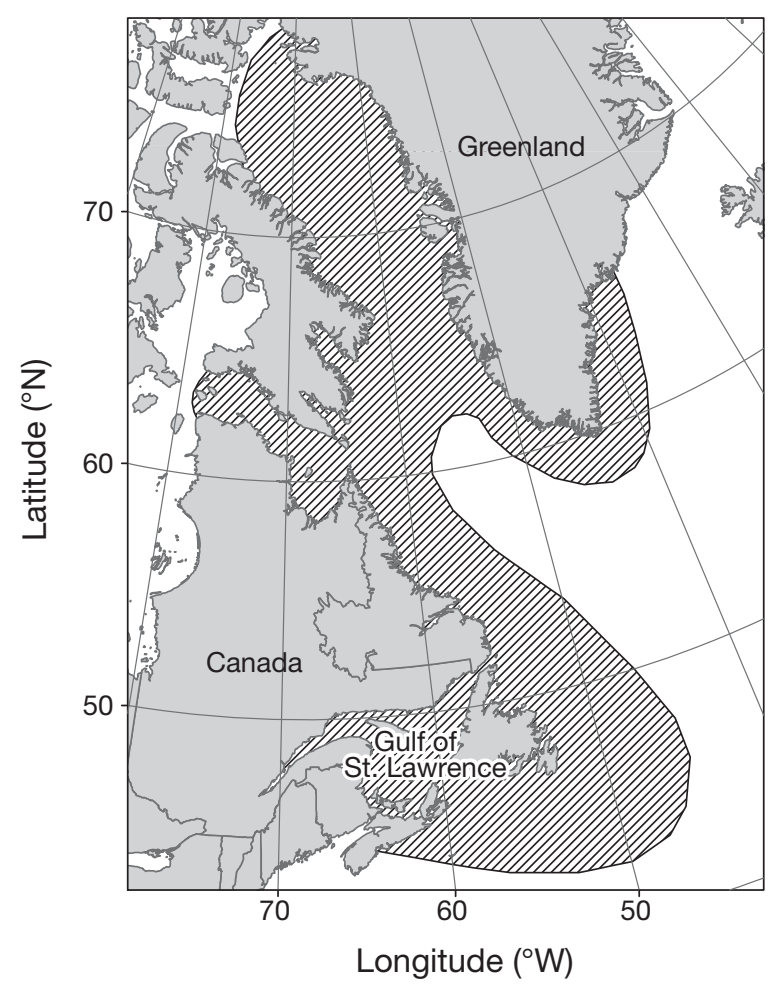

Fig. 2. Pagophilus groenlandicus. Distribution area of northwest Atlantic harp seals 


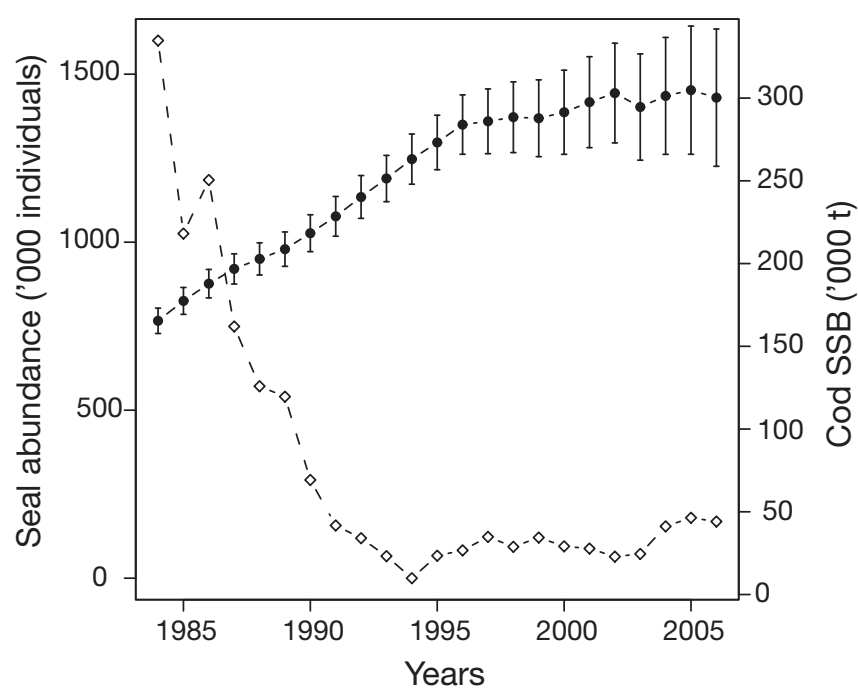

Fig. 3. Pagophilus groenlandicus. Harp seal abundance (•) (means $\pm \mathrm{SD}$ ) derived from the model of Hammill \& Stenson $(2004)$ and cod spawning stock biomass $(\diamond)$ derived from virtual population analysis (MPO 2007) in the northern Gulf of St. Lawrence during 1984 to 2006

account seasonal changes in seal feeding and variability in abundance, distribution and diet composition (Stenson et al. 1997, Hammill \& Stenson 2000, Stenson \& Hammill 2004). However, because of the variable nature of the seal diets, these models have assumed an average proportion of cod in the diet, in spite of the marked changes in cod biomass that have been documented over the last 3 decades (MPO 2007). Assumptions about how predation changes in response to variations in prey abundance have been shown to be critical in predicting impacts of predators on commercially important prey (Yodzis 1994, Mackinson et al. 2003). However, individual and population-level phenomena among predators and prey such as search image, difficulty in finding prey, aggregation, and dispersion of predator and prey, can lead to significant departures from the linear assumptions about the relationship between prey abundance and the proportion of prey in the diet (Koen-Alonso 2006). In addition, harp seals can display strong preference for specific prey, although they have been shown to be neutrally selective toward Atlantic cod (Lawson et al. 1998, Lindstrøm et al. 1998, Wathne et al. 2000). Modeling non-linear processes of the functional response of harp seals to cod therefore appears to be a key to modeling predation over a wide range of prey abundance such as observed in NGSL cod.

As described above, hypotheses related to fishing, seal predation, and environment have been proposed for the decline of NGSL cod, but few studies have attempted to simultaneously address these hypotheses to determine which processes were at play at different times and how synergistic forcing could have led to the cod collapse. Here, a predator-prey model was constructed for NGSL cod, with mortality partitioned into components caused by harp seal predation and by other processes, including an explicit influence of an integrated environmental forcer. The impact of seal predation on cod was modelled through a non-linear, multi-age functional response similar to a multi-species functional response (Smout \& Lindstrøm 2007). Cod condition was used as an index for the cumulative and lagged effects of environmental conditions related to factors such as food availability and temperature experienced by cod (Lambert \& Dutil 1997a,b, Rätz \& Lloret 2003). Changes in cod condition were assumed to affect natural mortality (Dutil \& Lambert 2000) and fecundity, i.e. potential recruitment strength (Marteinsdottir \& Begg 2002). The main objective of the analysis was to determine the relative impact of fishing, seal predation, and environment on the decline of NGSL cod by integrating these processes into a single consistent modeling framework. Such a framework is essential to both understand what happened to the stock and serve as a springboard for determining future states in the context of cod recovery and providing advice on exploitation of NGSL harp seal and cod populations.

\section{METHODS}

\section{Cod population model}

Cod population dynamics were modelled through a separable statistical catch-at-age analysis (Fournier \& Archibald 1982) without process error, where mortality was derived from 3 sources: the fishery, harp seal predation, and natural mortality due to causes other than harp seal predation (other predation, disease, virus, etc.). The Seal IMpact on Cod ABundance (SIMCAB) model considers 13 age classes of cod from age 1 to 13 , and $100 \%$ mortality occurs at the end of the age 13 class for all cohorts. Following Pope's approximation (Pope 1972), mortality processes were modelled as successive steps, i.e. removals of cod by harp seal predation were taken instantaneously at the beginning of the year, fishing removals were taken instantaneously in the middle of the year, and residual mortality occurred between the 2 portions of the year (see Table 2, D9-D11). The NGSL cod fishery changed considerably over the last decades, particularly after the 1994 moratorium when the winter mobile fishery, dominated by otter trawlers, was closed (Fréchet et al. 2003a). To account for changes in fishing patterns, 2 periods of distinct fishery selectivity (partial recruitment) were considered: 1984 to 1993 and 1994 to 2006. For consistency 
Table 1. Parameters and variables used in the Seal IMpact on Cod ABundance (SIMCAB) model. NS: data not shown

\begin{tabular}{|c|c|c|c|c|}
\hline Notation & Definition & Origin & Value & Equation \\
\hline$B$ & Cod biomass (t) & Calculated & NS & D1 \\
\hline$N$ & Cod abundance (no. ind.) & Calculated & NS & D1-D5, D9, D11-D12 \\
\hline$w$ & Cod weight (t) & Fixed & NS & D1-D2 \\
\hline SSB & Spawning stock biomass (t) & Calculated & NS & D2 \\
\hline TEP & Total egg production (no. of eggs) & Calculated & NS & D3, D8 \\
\hline$\xi$ & Sex ratio & Fixed & NS & D3 \\
\hline$\phi$ & Proportion of maturing females & Fixed & NS & D1, D3 \\
\hline$f$ & Fecundity (no. of eggs $\operatorname{cod}^{-1}$ ) & Fixed & NS & D3 \\
\hline A & Last age-group & Fixed & 13 & D3 \\
\hline$\lambda$ & $\begin{array}{l}\text { Functional responses of harp seals to cod } \\
\text { (no. consumed seal }{ }^{-1} \text { year }^{-1} \text { ) }\end{array}$ & Calculated & Fig. 9 & D4, D5 \\
\hline$\zeta$ & Attack rate (no. attacks seal ${ }^{-1} \mathrm{yr}^{-1}$ ) & Calculated & NS & D4 \\
\hline$\zeta$ ref & Reference attack rate (no. attacks seal ${ }^{-1}$ year $^{-1}$ ) & Calculated & NS & D4 \\
\hline$\rho$ & Scaling factor of the attack rates & Estimated & $0.021(0.003)$ & D4 \\
\hline$J_{\max }$ & $\begin{array}{l}\text { Maximum cod consumption rate } \\
\left(\text { no. consumed seal } \text { year }^{-1} \text { ) }\right.\end{array}$ & Calculated & 996 & D4 \\
\hline$m$ & $\begin{array}{l}\text { Shape parameter defining the functional } \\
\text { response type }\end{array}$ & Estimated & $2.13(0.015)$ & D4 \\
\hline$\rho$ & Feeding time spent by seals in Gulf each year (d) & Fixed & 150 & D5 \\
\hline $\bar{W}_{t}$ & Cod mean weight for age groups targeted by seals (t) & Calculated & NS & D5 \\
\hline $\bar{W}_{0}$ & $\begin{array}{l}\text { Cod mean weight for age groups targeted by seals in } \\
1998 \text { to } 2001(\mathrm{t})\end{array}$ & Calculated & $288 \mathrm{e}-6$ & D5 \\
\hline$S$ & Seal abundances (no. ind.) & Fixed & Fig. 3 & D5 \\
\hline$M$ & Residual natural mortality rate of cod $\left(\mathrm{yr}^{-1}\right)$ & Calculated & Fig. 7 & D6 \\
\hline$\alpha$ & Intercept of the $M$ curve $\left(\mathrm{yr}^{-1}\right)$ & Estimated & $5.03(0.013)$ & D6 \\
\hline$\beta$ & Slope of the $M$ curve & Estimated & $0.90(0.002)$ & D6 \\
\hline$\vartheta$ & Asymptote of the $M$ curve $\left(\mathrm{yr}^{-1}\right)$ & Calculated & NS & D6 \\
\hline$F$ & Fishing mortality rate of cod $\left(\mathrm{yr}^{-1}\right)$ & Estimated & Fig. 7 & D7 \\
\hline$\varsigma_{c}$ & Partial recruitment of cod & Calculated & NS & D7 \\
\hline$\gamma_{c}^{1}$ & Shape parameter of the partial recruitment (1984 to 1993) & Estimated & $1.95(0.007)$ & D7 \\
\hline$\delta^{1}{ }_{c}$ & $\begin{array}{l}\text { Age at which } 50 \% \text { of the individuals are vulnerable } \\
\text { to fishing gear (1984 to 1993) }\end{array}$ & Estimated & $5.39(0.006)$ & D7 \\
\hline$\gamma^{2}{ }_{c}$ & Shape parameter of partial recruitment of cod (1994 to 2006) & Estimated & $1.64(0.017)$ & D7 \\
\hline$\delta^{2}{ }_{C}{ }^{c}$ & $\begin{array}{l}\text { Age at which } 50 \% \text { of the individuals are vulnerable to } \\
\text { fishing gear (1994 to } 2006)\end{array}$ & Estimated & $6.46(0.016)$ & D7 \\
\hline$R$ & Cod recruitment (no. ind.) & Calculated & NS & D8 \\
\hline$R_{\max }$ & Maximum no. of cod recruits produced (no. ind.) & Estimated & $1.9 \mathrm{e} 9(6.9 \mathrm{e} 6)$ & D8 \\
\hline$r$ & $\begin{array}{l}\text { TEP needed to produce cod recruitment equal to } R_{\max } / 2 \\
\text { (no. of eggs) }\end{array}$ & Estimated & $5.3 \mathrm{e} 11(1.3 \mathrm{e} 11)$ & D8 \\
\hline$N^{\prime}$ & Cod abundance in the middle of the year (no. ind.) & Calculated & NS & D9-D10 \\
\hline$P$ & No. of cod predated by the seals (no. ind.) & Calculated & NS & D9 \\
\hline$C$ & Fishery catch (no. ind.) & Calculated & Fig. 6 & D10-D11, D14-D15 \\
\hline$I$ & Abundance index (no. ind.) & Calculated & Fig. 5 & D12 \\
\hline$\zeta_{s}$ & Survey selectivity & Calculated & NS & D12 \\
\hline$q$ & Survey catchability & Estimated & $1.38(0.076)$ & D12 \\
\hline$\gamma_{s}$ & Shape parameter of the survey selectivity & Estimated & $2.99(0.028)$ & D12 \\
\hline$\delta_{s}$ & $\begin{array}{l}\text { Age at which } 50 \% \text { of the individuals are vulnerable } \\
\text { to the survey gear (yr) }\end{array}$ & Estimated & $2.72(0.007)$ & D12 \\
\hline$p_{t, s}$ & Proportion of number in the survey (\%) & Calculated & NS & D13 \\
\hline$p_{t, c}$ & Proportion of catch (\%) & Calculated & NS & D15 \\
\hline
\end{tabular}

with available knowledge on NGSL cod dynamics and because of the convergence property of the virtual population analysis (VPA), the initial population agestructure was based on cod abundances estimated in 1984 from VPA (MPO 2007) and the model was run for the period 1984 to 2006 . The parameters and variables used and the process and observation equations are given in Tables 1 \& 2, respectively.
A condition-dependent reproduction function. Recruitment, i.e. fish numbers at age 1, was modelled through a Beverton \& Holt (1957) stock-recruitment relationship based on an index of the reproductive potential of cod that was developed from an estimate of total egg production of the stock (TEP) (Table 2, D3). TEP accounted for yearly changes in cod numbers-atage, sex ratio-at-age, the proportion of mature fe- 
Table 2. Deterministic process and observation equations in the SIMCAB model. $a$ : age; $t$ : time

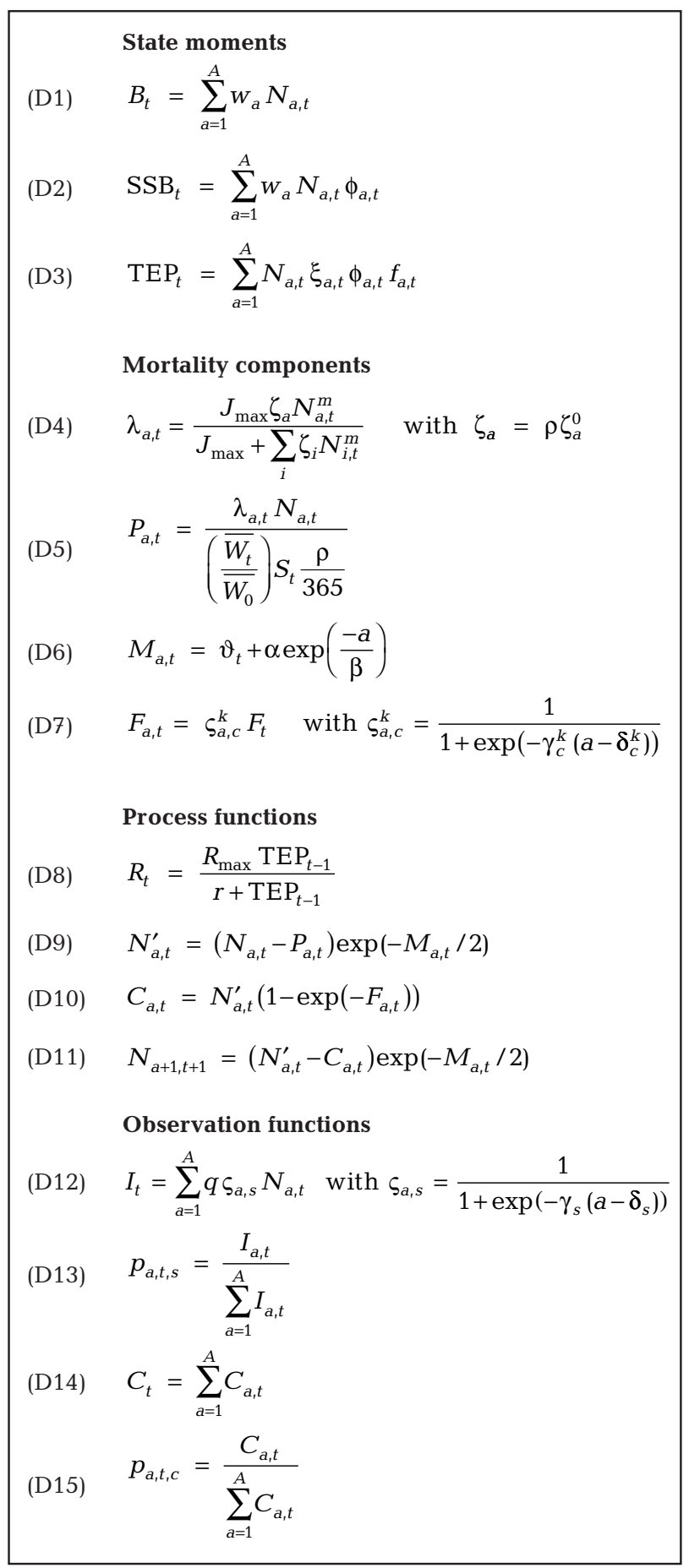

males-at-age, fecundity-at-age through length-at-age and condition factor of the fish. Previous studies have shown that length and condition factor have significant effects on the fecundity of cod in the NGSL (Lambert \& Dutil 2000, Lambert et al. 2000). This dependence of fecundity on length and condition factor was used to develop a generalized linear model to determine the variation in the fecundity between 1984 and 2006 (Lambert 2008).

Sex ratio and maturity ogive data were derived from winter surveys conducted with the MV 'Gadus Atlantic' (1984 to 1994) and spring samples available from the Groundfish Sentinel Fisheries Program (www.osl. gc.ca/pse/en/). Fulton's condition factor (Fulton 1902) based on length and weight data was also obtained from the winter surveys (1984 to 1994), the Sentinel Fisheries Program (1995 to 2007), and supplementary research surveys conducted during the pre-spawning period in 1994, 1995, 1997, and 1998 (Dutil et al. 2003, Fréchet et al. 2007).

A multi-age functional response of harp seals to cod. To account for effects of prey abundance on predation, assuming no predator interference in the predation process, a multi-age functional response (FR), i.e. the number of cod consumed per seal per year, was considered (Table 2, D4). The FR of seal to cod is comprised of a maximum consumption rate for $\operatorname{cod}\left(J_{\max }\right)$, attack rates-at-age $\left(\zeta_{a}\right)$, and age-structured cod population. The shape parameter $m$ of the FR determines the FR type, i.e. $m=1$ corresponds to a hyperbolic type 2 relationship and $m>1$ corresponds to a sigmoid shaped type 3 response (Koen-Alonso 2006).

The attack rates, $\zeta_{a}$, were expressed relative to baseline attack rates, $\zeta_{a}^{0}$ through a scaling factor, $\rho$, that was estimated in the fitting process (see section 'Fitting the model'). Baseline attack rates were derived from cod biomass requirements for the NGSL harp seal population, cod abundance based on the matrix of numbers-at-age derived from virtual population analysis (MPO 2007), that was extended to ages 1 to 2 based on preliminary runs of the model without predation, and proportion and age-structure of cod in the seal diet in 1998 to 2001.

First, harp seal energetic requirements to maintain the seal population were estimated based on the daily gross energy intake of an individual harp seal derived from the allometric Kleiber equation that scales animal's metabolic rate to the 3/4 power of the animal's mass, and the age-structure of the seal population (Hammill \& Stenson 2004, Stenson \& Hammill 2004). $25 \%$ of the northwest harp seal population was assumed to move into the Gulf of St. Lawrence each year to spend on average $150 \mathrm{~d} \mathrm{yr}^{-1}$ in its northern part (Stenson et al. 2002, 2003). The biomass of cod consumed in 1998 to 2001 was then estimated based on the average energy content of cod in winter, set to $4.96 \mathrm{~kJ} \mathrm{~g}^{-1}$ (Lambert \& Dutil 1997a), and on the annual average proportion of cod in seal diets during November to March 1998-2001 (Table 3). The relative energetic contribution of cod to seal diets was estimated from recovered otoliths and accounted for harp seal 
Table 3. Gadus morhua. Proportion of Atlantic cod in harp seal diet weighted by their relative residency in each area during the period November to March. Years indicate the period of November of the listed year to March of the following year. -: not determined

\begin{tabular}{|c|c|c|c|c|}
\hline Year & 4 Ra-c & \multicolumn{2}{|c|}{ Sample size } & Proportion \\
\hline 1998 & 27 & 21 & - & 0.0506 \\
\hline 1999 & 28 & 22 & 24 & 0.0538 \\
\hline 2000 & 25 & 39 & 29 & 0.0382 \\
\hline 2001 & 30 & 16 & - & 0.0377 \\
\hline
\end{tabular}

population residency in the areas $4 \mathrm{Ra}-\mathrm{C}, 4 \mathrm{Rd}-3 \mathrm{Pn}$, and $4 \mathrm{~S}$ of the NGSL (Hammill \& Stenson 2004). The annual number of cod consumed by harp seals was then estimated based on the mean mass of cod consumed and reallocated between cod age-groups using information available from the analysis of seal stomach contents (Lawson et al. 1998, Hammill \& Stenson 2004). Lengths of ingested cod were estimated from otoliths found in seal stomachs and published fish length-otolith length regression equations (Hammill \& Stenson 2004). Otoliths collected from stomach contents were assumed to represent the size distribution of cod eaten. Fish lengths were based on 671 otoliths found in 140 seal stomachs collected during November to March 1989-2001 in the Gulf of St. Lawrence (Chassot et al. 2007). Harp seal size ranged from 102 to $166 \mathrm{~cm}$. Proportions were estimated by fitting a mixture model of normal distributions to the prey size-frequency histogram by applying a constraint on the variance of cod size derived from the DFO summer surveys (Chassot et al. 2007).

The maximum consumption rate, $J_{\max }$, was calculated based on the energy requirements of the NGSL harp seal population in 1998 to 2001, and a maximum value of cod proportion in seal stomachs was derived from available diet information. Following the same approach as described above, fish biomass required to maintain the NGSL seal population was first calculated. Based on a maximum proportion of $18.3 \%$ of cod in seal diets observed since 1980 and the relative residency time of seals in each area of the NGSL, the potential maximum number of cod eaten per seal per year, $J_{\text {max }}$ was calculated. The baseline attack rates-at-age were finally calculated from the number of cod-at-age consumed per seal, and cod numbers-at-age were derived from the VPA in 1998 to 2001 (Table 2, D4). Since the baseline attack rates were based on the number of cod eaten calculated from the mean weight of cod in the reference period 1998 to 2001 , the mass ratio $\bar{W}_{t} / \bar{W}_{0}$, an index of cod weight, was included to account for yearly fluctuations in the mean mass of cod when calculating the number of cod predated by seals (Table 2, D5).
In order to illustrate the multi-age functional feeding response to changes in cod availability, a large range of levels of cod abundance were simulated for 2 distinct age-structures of the cod population. For each age-structure, cod-at-age consumed per seal per year were calculated based on the model fitting results.

Removals by natural mortality other than harp seal predation. The rate of natural mortality excluding harp seal predation, i.e. residual mortality, was modelled as an age-dependent function in the form of a decreasing exponential as a function of age with a conditiondependent asymptote (Table 2, D6). The asymptote was modelled as a decreasing linear function of cod condition based on results of laboratory experiments relating natural mortality to cod condition (Dutil \& Lambert 2000, Chassot et al. 2007). The condition factor, which is an indicator of the energy content of cod, was used here as an integrative index of environmental conditions (Lambert \& Dutil 1997b). Alternative values for the asymptote of the residual mortality curve, i.e. a constant value of $0.4 \mathrm{yr}^{-1}$, and a time-dependent natural mortality derived from stock assessment models (MPO 2007) were considered to assess the impact on the results through the Akaike Information Criterion (AIC; Akaike 1974).

Effects of seal predation vs. fishing on the reproductive potential. Because seal predation and fishing are mortality sources for different cod age groups, a unit of mortality of each does not have the same impact on the population. Similarly to a multi-fleet biomassper-recruit analysis, effects of changes in harp seal predation vs. fishing mortality were investigated by calculating the spawning stock biomass per recruit (SSB/R) for different levels of mortality. Such an analysis focuses on the long-term survival of a recruit and does not consider the linkage between reproductive potential and recruitment at age 1 . Based on the mortality rates estimated and averaged over the period 2002 to 2006 and assuming all else constant, we examined the relative importance of seal predation mortality and fishing mortality on the long-term stock reproductive potential under 2 scenarios: a high productivity environment and a low productivity environment. Considering a range of fishing mortality multipliers from 0 to 2 , cod SSB/R was calculated at equilibrium for distinct levels of condition, because the condition of cod was assumed to affect the asymptote $\vartheta$ of the residual natural mortality in the model. Three levels of seal predation mortality were considered, corresponding to $0.5,1$, and 1.5 times the average harp seal predation mortality estimated for 2002 to 2006. Two scenarios of condition represented different environmental parameters for the cod population, with values of $\vartheta=0.26$ and $\vartheta=0.35$ corresponding to a high and a low productivity regime scenario, respectively. 


\section{Fitting the model}

Abundance and catch data. Stratified, random bottom trawl surveys have been conducted in the NGSL annually, in summer months, since 1984. A consistent time series of numbers-at-age, accounting for the changes in research vessels and fishing gear, was used as abundance indices for cod for the period 1984 to 2006 (Bourdages et al. 2003, 2007, Chassot et al. 2007).

The catch-at-age matrix of cod (total number of individuals) was obtained from the last updated stock assessment carried out in February 2007 (MPO 2007). All quantities caught and landed for both commercial and recreational fisheries, excluding discards, were included in the data. In the present analysis, reported landings were considered as the 'true' catch despite potential discarding and misreporting in the fishery (Fréchet et al. 2003b, Savenkoff et al. 2004).

Statistical estimation approach. Maximum likelihood methods were used to estimate SIMCAB parameters. The likelihood function of the model was derived from assumptions on the statistical distribution of the 4 datasets acquired from independent sampling processes: total abundance index in number of individuals, proportion-at-age for the abundance indices, total catch in number of individuals, and proportion of catch-at-age (Fournier \& Archibald 1982, Quinn \& Deriso 1999) (Table 4).

A stochastic observation equation accounting for correlated errors among ages was considered to link the abundance indices to the population model (Myers \& Cadigan 1995) (Table 4, S1). For some years, some abundance indices-at-age for very young (age 1) or old cod (ages 11 to 13) were not observed during the surveys. For these years, total survey indices were considered as right-censored data, providing less information to the likelihood component than real observations (Lawless 2003). This is true for the sum over ages of the logarithms of the survey indices, since these indices are extrapolated to the scale of the NGSL and are positive numbers greater than 1 . The observed likelihood of total survey indices was then composed of a product of densities and survival functions, where a survival function is defined as 1 minus the distribution function (Table 5, L1). The survival factor in the likelihood represents the integration, over all its possible values, of the probability that a random total survey index is higher than an under-

Table 4. Definitions used to extend the deterministic model in Table 1 to a stochastic model. iid: independent and identically distributed; $\sim$ : distributed as; $\mathcal{N}$ : normal distribution; Dir: Dirichlet distribution. See Table 6 for notation definitions

(S1) $\quad J_{t}^{*}=\sum_{a=1}^{A} J_{a, t}^{*} \stackrel{\text { iid }}{\sim} \mathcal{N}\left(\sum_{a=1}^{A} \log I_{a, t}(\theta), \psi^{2}\right) \quad \psi^{2}=A \sigma^{2}+A^{2} \tau^{2}$ where $J_{a, t}^{*}=\log \left(I_{a, t}^{*}\right)=\log \left(I_{a, t}\right)+\epsilon_{a, t}+\eta_{t} \quad \epsilon_{a, t} \stackrel{i i d}{\sim} \mathcal{N}\left(0, \sigma^{2}\right)$ $\eta_{t} \stackrel{i i d}{\sim} \mathcal{N}\left(0, \tau^{2}\right)$

$$
p_{a, t, s}^{*} \stackrel{i i d}{\sim} \operatorname{Dir}\left(p_{1, t, s}(\theta), \ldots, p_{A, t, s}(\theta), n_{t, s}^{*}\right)
$$

$$
p_{a, t, c}^{*} \stackrel{i i d}{\sim} \operatorname{Dir}\left(p_{1, t, c}(\theta), \ldots, p_{A, t, c}(\theta), n_{t, c}^{*}\right)
$$

$$
\log C_{t}^{*} \stackrel{i i d}{\sim} N\left(\log C_{t}(\theta)-\frac{\sigma_{c}^{2}}{2}, \sigma_{c}^{2}\right)
$$

Table 5. Likelihood components of the SIMCAB model. The generic notation $\theta$ represents the set of parameters to estimate. See Table 6 for notation definitions

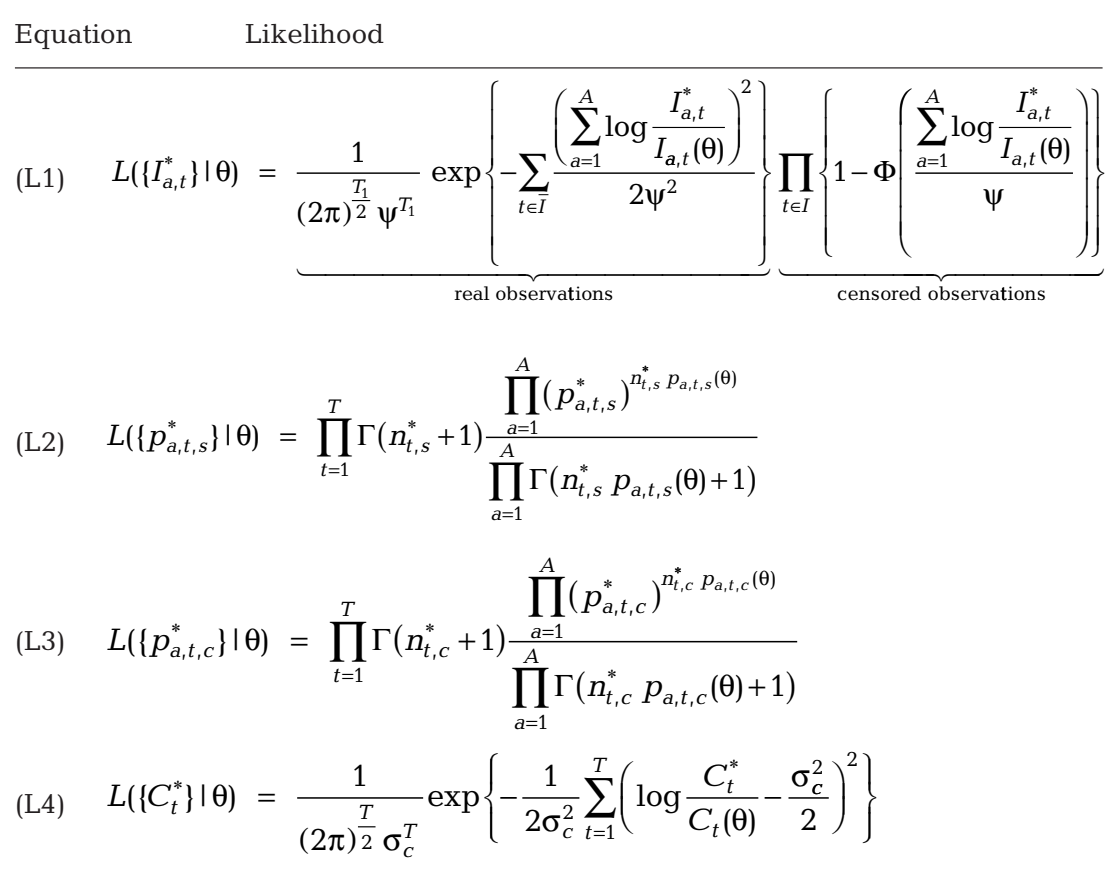


reported observation. It is a common way of including partial data information in a statistical analysis, but rarely used in fisheries analysis (for a notable exception see Hammond \& Trenkel 2005).

Proportion-at-age for the abundance indices and catch data were assumed to follow Dirichlet distributions to account for correlations among age groups (Fournier \& Archibald 1982) (Table 4, S2 \& S3). Total catch observed was considered mainly dependent on the fishing year and assumed to include lognormal observation errors (Table 4, S4). The assumption of log-normal error distributions for survey and catch data was checked through the residuals.

The maximum likelihood estimates were found by minimizing the negative sum of the log of the 4 likelihood components (i.e. objective function) given in Table 5. Minimizations were performed with the Nelder-Mead simplex non-linear optimization algorithm implemented in the $\mathrm{R}$ package ( $\mathrm{R}$ Development Core Team 2008). The parameter space $\theta$ to estimate included 37 parameters from 644 observations, an observation being a survey index or catch number for a given age group in a given year: 2 for the TEP-recruitment relationship $\left(R_{\max }\right.$ and $r$ ), 2 for the FR ( $m$ and $\rho$ ), 2 for the residual mortality curve ( $\alpha$ and $\beta$ ), 1 for the survey catchability $(q), 6$ for the selectivity of survey and fishing gears $\left(\gamma_{s \prime} \delta_{S^{\prime}} \gamma_{C^{\prime}}^{1} \delta_{{ }^{\prime}{ }^{\prime}} \gamma_{C^{\prime}}^{2} \delta^{2}{ }_{c}\right), 23$ for the fishing mortality rates $\left(F_{t}\right)$, and 1 for the standard deviation of the observation error in the total survey data $(\psi)$ (see Table 1 for definition). The value of the observation error variance in the total catch data $\left(\sigma^{2}{ }_{c}\right)$ at the maximum liklihood estimate was:

$$
\sigma_{c}^{2}=2\left(\sqrt{1+\frac{1}{T} \sum_{t=1}^{T}\left(\log \frac{C_{t}^{*}}{C_{t}}\right)^{2}}-1\right.
$$

where the notations used are given in Table 6.

Confidence statements about parameters were inferred using parametric bootstrap methods accounting for bias (Efron \& Tibshirani 1998). We generated 100 bootstrap replicate samples with the same dimensions as the datasets described above by drawing from the probability distributions characterised by the parameters estimated at the maximum likelihood. Replicate samples were then submitted to the estimation procedure to obtain bootstrap replicates of the estimator and calculate percentiles of the distribution.
Sensitivity analysis. To complete the bootstrap analysis that only considered uncertainty in the catch and survey data, a sensitivity analysis was performed to account for uncertainty in some input parameters of the predation model and harp seal population in the NGSL (Hammill \& Stenson 2004, Stenson \& Hammill 2004). In a first step, the sensitivity of the results was examined by independently increasing parameter values by $10 \%$ from a baseline value (values from the standard run), re-fitting the model to observations for each sensitivity run, and assessing the change between the new and baseline results through a measure of relative sensitivity (Mohn \& Bowen 1996, Stenson \& Hammill 2004). The sensitivity to 5 parameters was investigated: the proportion of the northwest Atlantic population of harp seals moving into the NGSL, the average proportion of cod in seal diets in 1998 to 2001, the maximum proportion of cod in seal diets, the average energy of cod, and the Kleiber multiplier used as a constant multiplicative parameter in the Kleiber equation (Table 7). In order to summarize the model results and because predation by harp seals was the main focus of the analysis, only results for mean cod biomass removed by seals and mean predation mortality rate for ages 1 to 4 during 1984 to 2006 were presented. In a second step, the impacts of setting the value of the functional response type $m$ to 1 , i.e. a hyperbolic type 2 relationship, were examined.

Table 6. Parameters and variables used in the stochastic equations and likelihood components. $a$ : age; $t$ : year; $s$ : survey; $c$ : catch

\begin{tabular}{|c|c|c|}
\hline Notation & Definition & Equation \\
\hline$I^{*}{ }_{a, t}$ & Observed abundance index & L1 \\
\hline$J^{*}{ }_{a, t}$ & Log-observed abundance index $T_{1}=$ Card $(\bar{I})$ & S1 \\
\hline$T_{1}$ & Number of uncensored data, with & L1 \\
\hline$\Phi$ & Cumulative standard normal distribution & L1 \\
\hline$\psi$ & Standard deviation of the observation error in the survey data & L1 \\
\hline$n^{*}{ }_{t, s}$ & Observed total number of fish taken by the survey vessels & L2 \\
\hline$p^{*}{ }_{a, t, s}$ & Observed proportion of number-at-age, with $p_{a, t, s}^{*}=\frac{I_{a, t}^{*}}{\sum_{a=1}^{A} I_{a, t}^{*}}$ & L2 \\
\hline$p_{a, t, s}$ & Predicted proportion of number-at-age & L2 \\
\hline$T$ & Number of years & L2-L4 \\
\hline$\Gamma$ & Gamma distribution & L2-L3 \\
\hline$p^{*}{ }_{a, t, c}$ & Observed proportion of catch-at-age & L3 \\
\hline$p_{a, t, c}$ & Predicted proportion of catch-at-age & L3 \\
\hline$n_{t, c}^{*}$ & Total catch sampled to establish age-proportions & L3 \\
\hline$C^{*}{ }_{t}$ & Observed total catch & L4 \\
\hline$C_{t}$ & Predicted total catch & L4 \\
\hline$\sigma_{c}$ & Standard deviation of the observation error in the catch data & L4 \\
\hline
\end{tabular}


Table 7. Relative sensitivity (\%) of biomass removed (BR) by seals and predation mortality rate for cod aged 1 to $4 \mathrm{yr}\left(\mathrm{M}_{\mathrm{p}}(1-4)\right)$ to a $10 \%$ increase in input parameters. NGSL: northern Gulf of St. Lawrence

\begin{tabular}{|lcrc|}
\hline Parameter & Base value & BR & $\mathrm{M}_{\mathrm{p}}(1-4)$ \\
\hline \% in the NGSL & 25 & 67 & 129 \\
\% cod contribution to diet 1998 to 2001 & 4.53 & 1 & 25 \\
\% cod maximum contribution to diet & 18.3 & -6 & -2 \\
Average energy content of cod ( $\mathrm{kJ} \mathrm{g}^{-1}$ ) & 4.96 & -13 & 40 \\
Kleiber multiplier (kJ) & 293 & 67 & 129 \\
\hline
\end{tabular}

\section{RESULTS}

\section{Age-structure of cod in seals' diet}

The size-frequency histogram showed that $95 \%$ of cod found in harp seal stomachs were less than $38 \mathrm{~cm}$ in length (Fig. 4). The mixture model fitted the cod sizefrequency data well as indicated by the significance level for the goodness-of-fit test ( $p>0.05)$, based on the chi-square approximation to the likelihood ratio statistic ( $\mathrm{Du}$ 2002). The model showed that cod consumed were young, with ages 1 to 4 representing 26.5, 48.5, 18 , and $7 \%$ of the cod in seal diets, respectively (Fig. 4).

\section{Cod population dynamics}

The model fitted the survey and catch data well and the minimum value for the objective function was 6149.6, corresponding to an AIC value of 12373 (Figs. $5 \& 6$ ). The

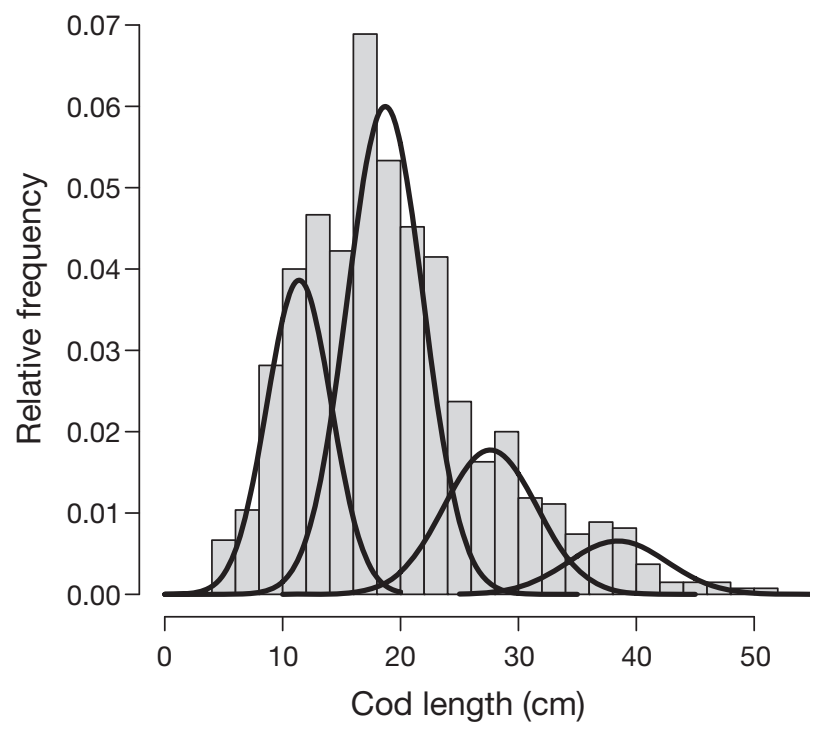

Fig. 4. Gadus morhua. Size-frequency histogram of cod ingested by harbor seals, derived from otoliths collected in seal stomachs, with fitted mixture distribution representing cod of age 1 to $4 \mathrm{yr}$ variances of the observation errors in the survey and catch data were low, the values of $\psi$ and $\sigma_{C}$ used as proxies of coefficients of variation in the case of lognormal likelihoods being 5.0 and $2.7 \%$, respectively. Consequently, confidence intervals around parameters estimated by bootstrap analysis were small (Table 1). Considering a constant asymptote of $0.4 \mathrm{yr}^{-1}$ and a variable asymptote for the residual mortality curve led to higher values of AIC (12583 and 12696 respectively) than for a condition-dependent asymptote, indicating a better fit of the model when residual mortality was related to cod condition.

SIMCAB estimates indicated a strong decline in cod abundance for all age groups from 1984 to 1993, consistent with the collapse of the northern Gulf cod stock in the mid-1990s (Fig. 5). Abundance indices for ages 4 to 8 then remained quite stable from the mid-1990s to the early 2000s, the stock showing no clear sign of recovery despite the moratoria on fishing implemented in 1994 to 1996 and 2003 (Fig. 5). By contrast, abundance indices for cod aged 10 to 13 displayed increasing trends from the mid-1990s to the 2000s; these agegroups represented a very small proportion of the stock abundance but about $10 \%$ of the SSB on average for the period 1984 to 2006 (Fig. 5). The declines in total cod abundance were accompanied by a decrease in SSB from more than $330000 \mathrm{t}$ in the early 1980s to a minimum of less than $30000 \mathrm{t}$ in 1994 and showed a small increase thereafter. SSB estimates were thus below the conservation biomass limit of 80000 to $90000 \mathrm{t}$ and indicated a clear case of recruitment overfishing for the stock.

The number of cod caught showed a strong decrease from the 1980s to the mid-1990s for ages 5 to 10 that represent the large majority of the harvested biomass (Fig. 6). SIMCAB predictions appeared bumpy in the 1980s, with catches underestimated in 1986 and 1988 for all age-groups (Fig. 6). This mismatch between observed and predicted catch seems mostly due to the exceptional and somewhat surprising abundance indices for ages 4 to 10 in 1987 (Fig. 5).

\section{Mortality components in different age-groups}

Total mortality divided into age-groups showed that sources and magnitude of mortality varied in time and age (Fig. 7). Young cod aged 1 to 2 yr experienced high natural mortality, varying between about $1.9 \mathrm{yr}^{-1}$ in the mid-1980s to more than $2.4 \mathrm{yr}^{-1}$ in the mid-1990s (Fig. 7a). Predation mortality by harp seals only represented a low proportion of mortality for ages 1 to 

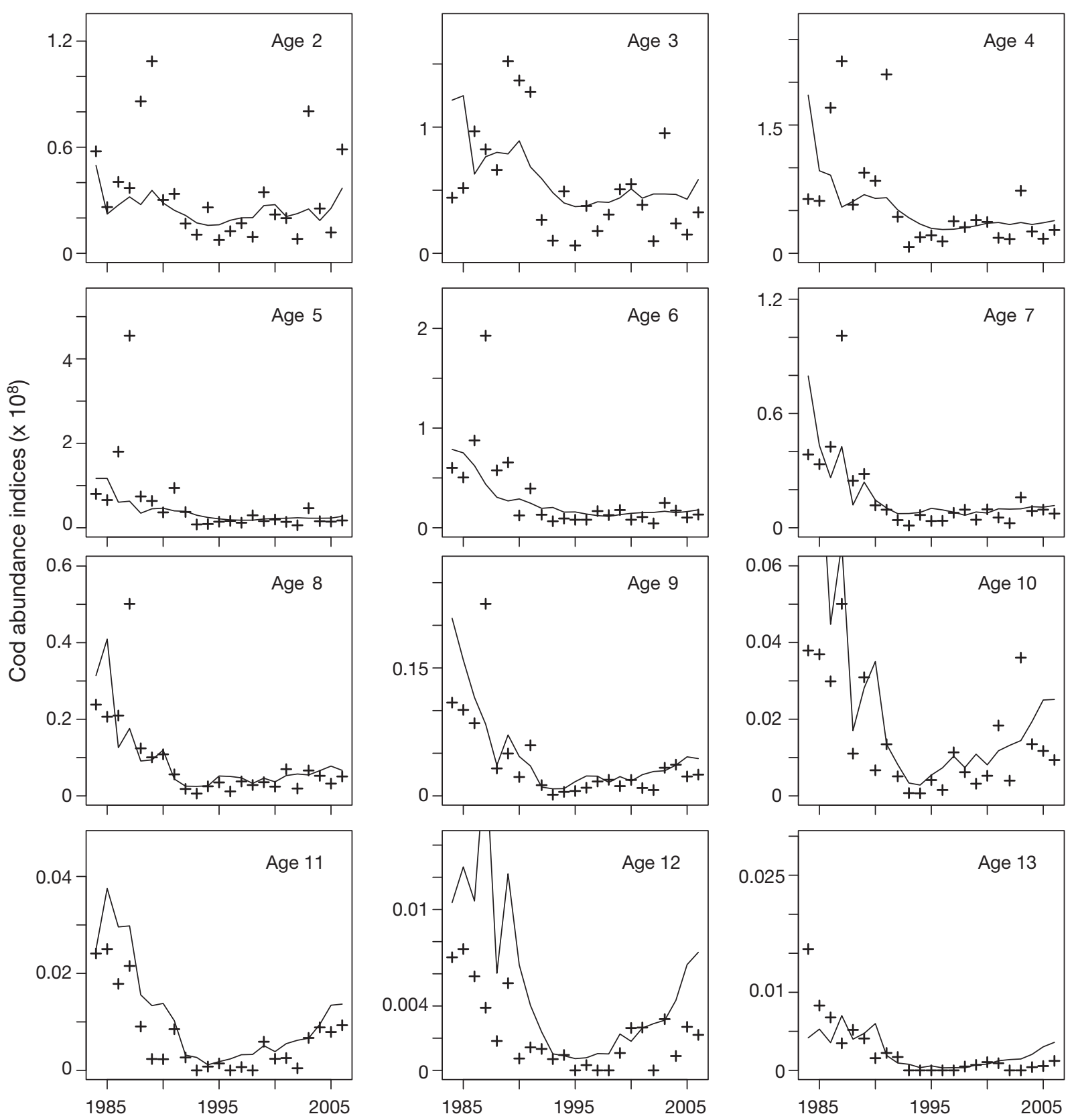

Fig. 5. Gadus morhua. Survey numbers-at-age observed (+) and predicted by the Seal IMpact on Cod ABundance (SIMCAB) model (solid line). Scales were selected for readability along $y$-axes

2 throughout the period 1984 to 2006 but increased from about $6 \%$ in the 1980 s to more than $12 \%$ in the mid-2000s.

In addition to seal predation and residual natural mortality, cod aged 3 to 6 were subject to fishing mortality, mainly in the 1980s (Fig. 7b). The decrease in fishing mortality from the mid-1990s coincided with the change in fishing pattern, i.e. the commercial fishery after 1994 was only conducted by fixed gears (longlines, gill nets, and hand lines) targeting larger cod. Residual natural mortality showed an increase from the 1980s to the mid1990s associated with lower condition during this period; the rates in the most recent years were similar to the levels estimated in the mid-1980s. Seal predation mortality for ages 3 to 6 remained quite stable during 1984-2006 with its proportion in total mortality increasing to more than $20 \%$ in the 2000 s due to the decrease in fishing and residual natural mortality.

Cod aged 7 to 10 not preyed upon by harp seals showed high total mortality, particularly in the mid- 

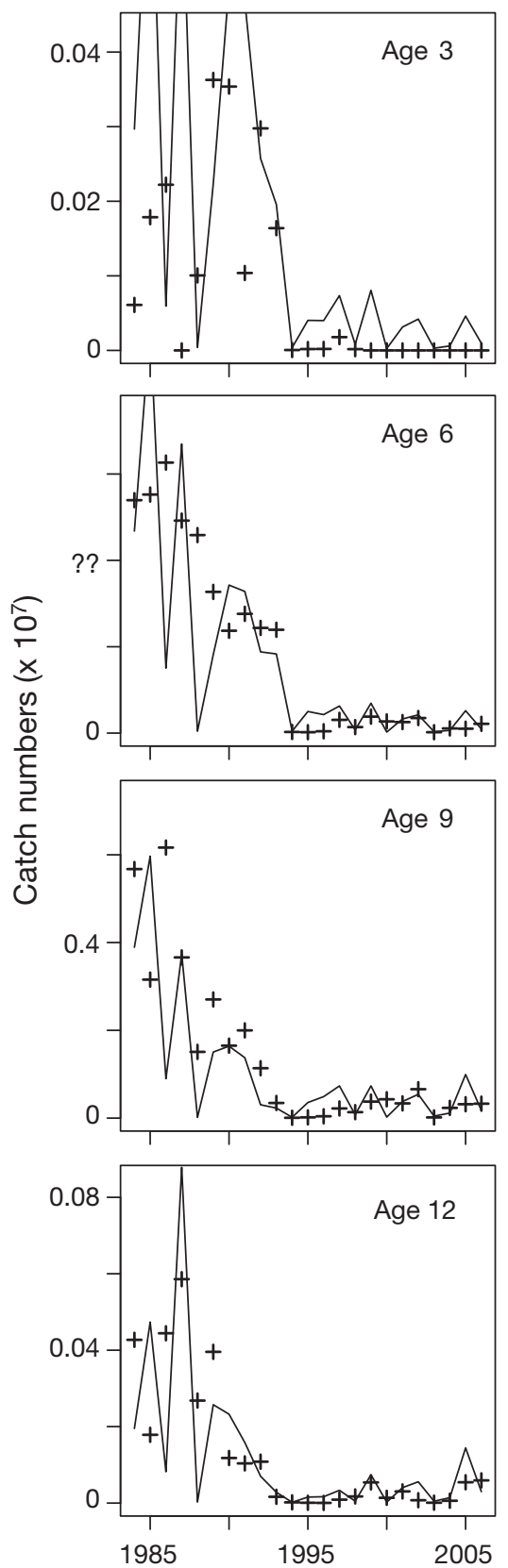
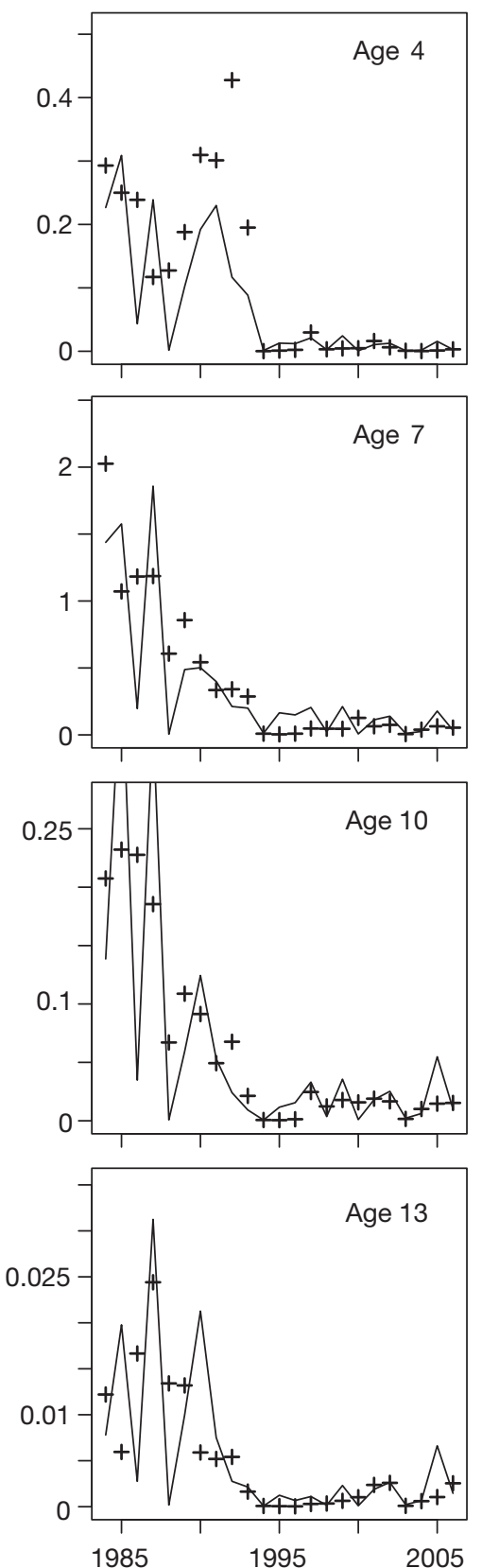
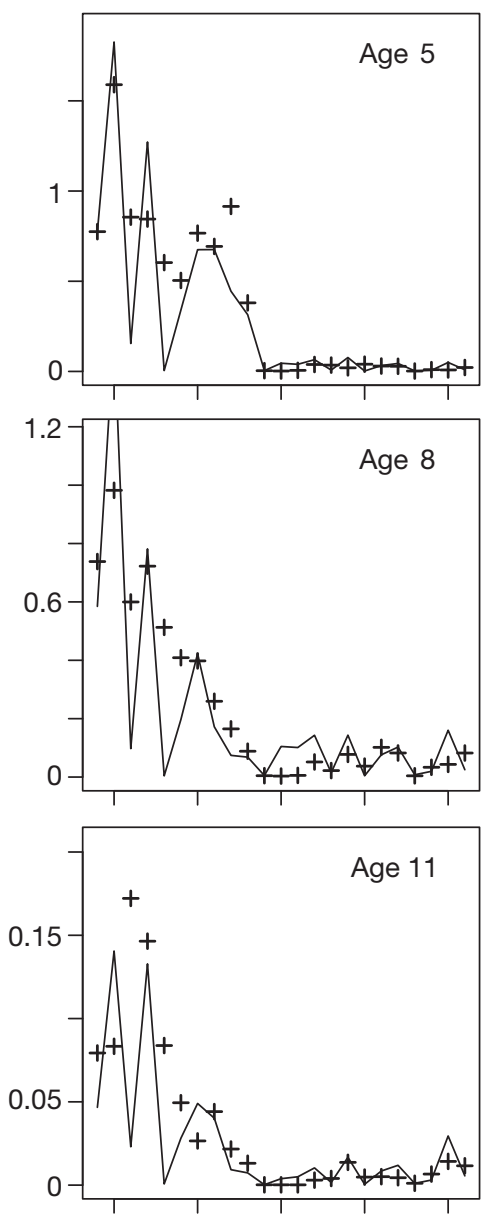

Fig. 6. Gadus morhua. Catch-atage observed $(+)$ and predicted by the SIMCAB model (solid line). Scales were selected for readability along $y$-axes 1980s and early 1990s with rates higher than $1.0 \mathrm{yr}^{-1}$ (Fig. 7c). The high interannual variability in mortality rates was mainly due to the strong variations in fishing mortality that represented more than $65 \%$ of the total mortality in some years (Fig. 7c). The low fishing mortality values estimated in 1986 and 1988 could be due to the high abundance indices observed in 1987 (Fig. 5). As for ages 3 to 6, residual natural mortality was the highest in the mid-1990s, corresponding to a low-condition period for cod. Although fishing mortality rates showed a decreasing trend in the 2000s, the values remained high for some years relative to the low abundance of the stock, particularly in 2005.

\section{Harp seal predation}

Predation mortality rates for cod aged 1 to 4 showed a steady increase alongside the increase in harp seal abundance from $0.1 \mathrm{yr}^{-1}$ in 1984 to more than $0.3 \mathrm{yr}^{-1}$ in 2000 (Fig. 8). The rates then decreased to remain quite stable around $0.25 \mathrm{yr}^{-1}$ in the most recent years. Cod biomass removed annually by seal predation was estimated to be around 10000 t from 1985 to 1995 . Removals then showed an increasing trend with a peak above $30000 \mathrm{t}$ in 2000 and a temporally averaged median of $16000 \mathrm{t}$ in the 2000s. The high interannual variability in biomass 

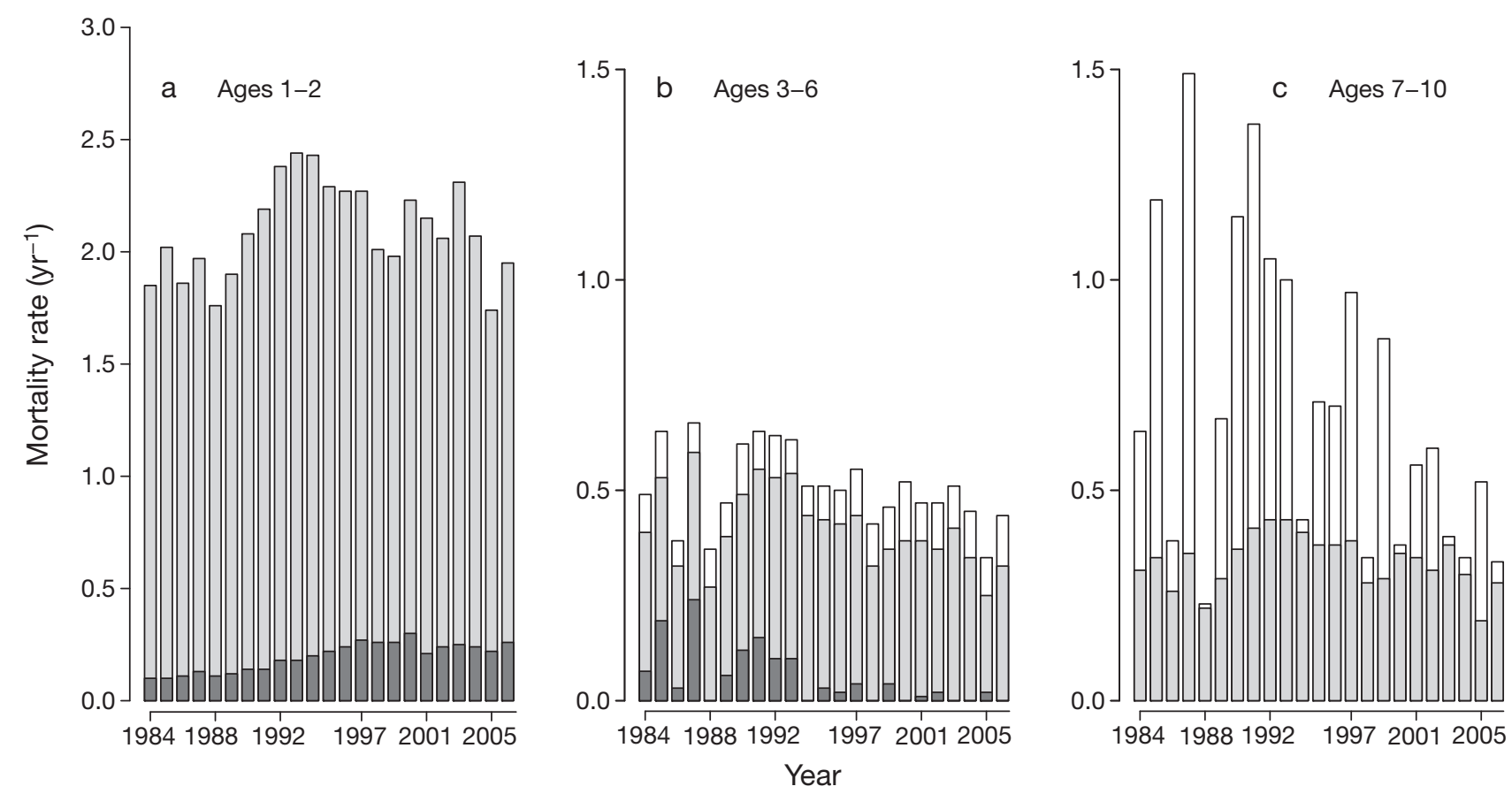

Fig. 7. Gadus morhua. Cumulative annual mortality rates for cod (a) aged 1 to 2, (b) aged 3 to 6, and (c) aged 7 to 10. Dark grey: seal predation mortality; light grey: natural mortality other than by seal predation; white: fishing mortality. Scales were selected for readability along $y$-axes

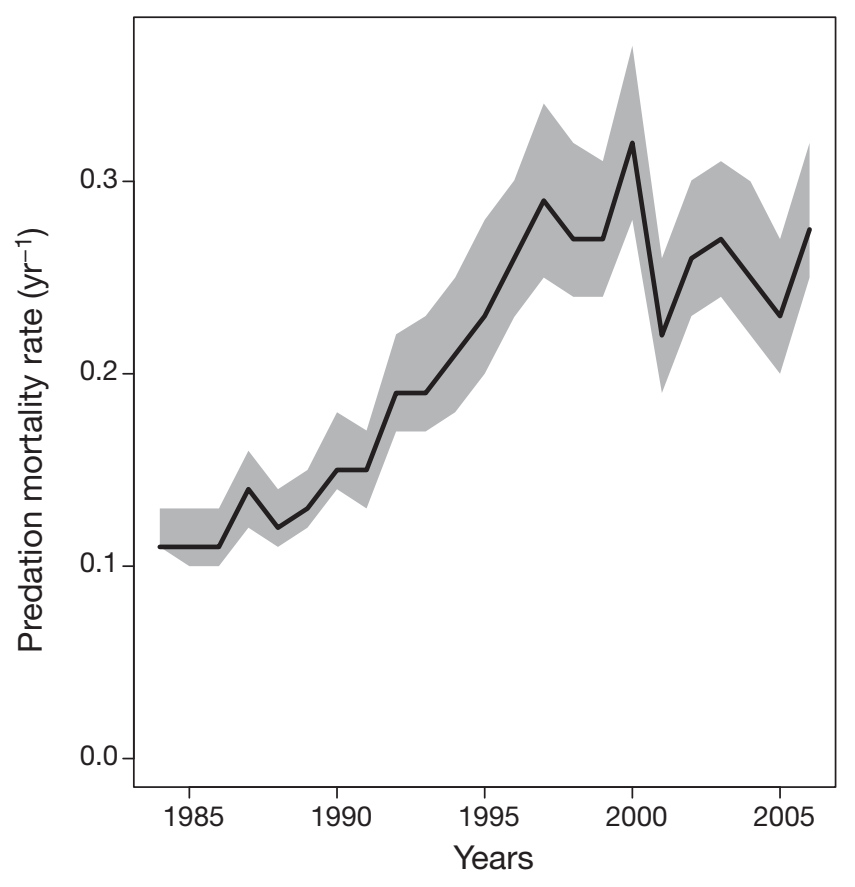

Fig. 8. Gadus morhua. Annual seal predation mortality rate for cod aged 1 to 4, with $90 \%$ bootstrap confidence intervals

removed was mainly due to the variations in abundance of cod aged 1 to 2 that represent the major age-groups preyed upon by harp seals.
The exponent of the multi-age functional response fitted to the data was estimated to be 2.13 ( \pm 0.015 ), indicating a sigmoid shaped type 3 response characteristic of sharp changes in the relative importance of the cod age-groups consumed as the result of a relatively small change in their availability in the environment. The changes in biomass removed by seal predation were then related to both changes in seal population energy requirements and changes in relative cod abundance between age-groups. For instance, the predicted multi-age functional response showed that cod age 2 would be the main target of harp seals when considering different levels of cod abundance described by the 1984 population age-structure (Fig. 9). Considering an age-structure similar to low abundance year of 1995, characterized by a high proportion of cod aged 1 in the population, would lead to a very different response of seals with age-1 cod becoming the major prey and the other age-groups quickly reaching their respective maximum in seal consumption (Fig. 9).

\section{Sensitivity analysis}

The sensitivity analysis showed that the results of the model concerning harp seal predation were robust to the assumptions made about the average energy of cod and the values of contribution of cod to seal's diet 


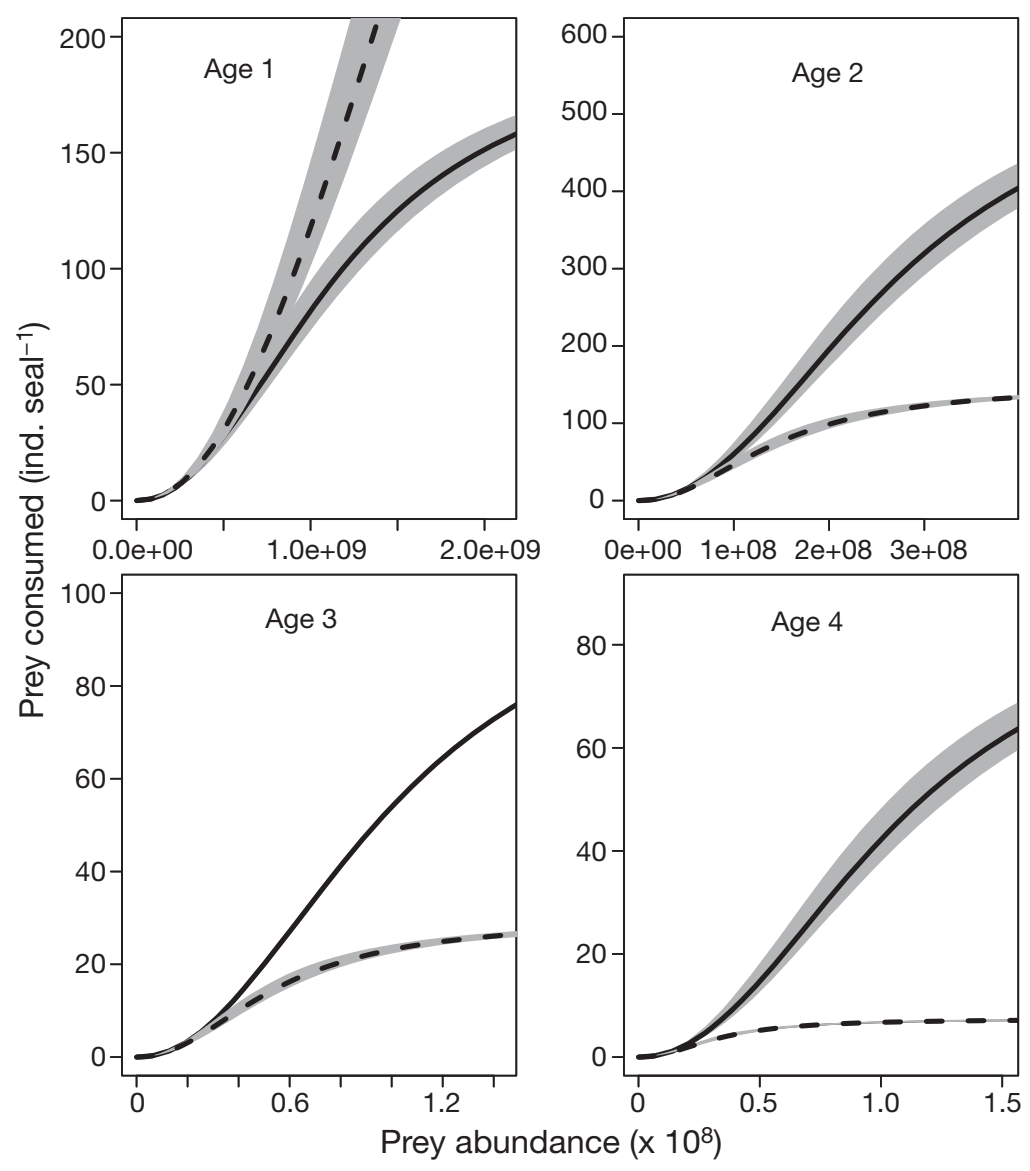

Fig. 9. Predicted multi-age functional response of harp seal to cod for 2 distinct age-structures of the population. Solid line corresponds to the age-structure in 1984; dashed line corresponds to the age-structure in 1995, characterized by a high abundance of cod aged 1 . Grey area represents $90 \%$ bootstrap confidence intervals. Scales were selected for readability along $y$-axes
Constraining the predation model to follow a hyperbolic type 2 relationship strongly affected the results of the model and resulted in a lower quality of fit than for the standard run (AIC = 12697 ). Setting the shape parameter of the functional feeding response to 1 led to reduced harp seal predation and increased cod numbers-at-age and spawning stock biomass.

\section{Effects of seal predation vs. fishing on the reproductive potential}

The SSB/R curves showed that the reproductive potential of the NGSL cod was affected differently by changes in seal predation and fishing mortality (Fig. 10). The distinct productivity regimes represented by 2 levels of residual mortality modified the values of $\mathrm{SSB} / \mathrm{R}$, with low productivity leading to lower values of SSB. In both cases of productivity regimes, the nearly horizontal curves indicated that changes in SSB/R would be poorly modified by changes in fishing mortality while variations in seal predation mortality would have a higher effect on SSB/R (Fig. 10). This result was mainly due to the low fishing mortality rate of $0.15 \mathrm{yr}^{-1}$ esti-
(Table 7). Increasing the contribution of cod to seal's diet in 1998 to 2001 did not affect the total biomass removed but led a relatively small increase in predation mortality rates by decreasing the cod population. Although the increase in maximum cod consumption led to an increase in the maximum rate of cod consumption $J_{\text {max }}$ it poorly affected harp seal predation. Predation appeared quite sensitive to a change in the size of the seal population and the Kleiber multiplier of the bioenergetic model (Table 7). Changes in input parameters could be counter-intuitive due to the complexity and non-linearity of the model; hence, the biomass removed by predation during 1984 to 2006 was decreased by an increase in average energy of cod while it led to an increase in the predation mortality rates. The relative sensitivity of predation rates could have a different sign than the sensitivity of biomass removed since predation rates depend both on the cod biomass removed and cod numbers-at-age.

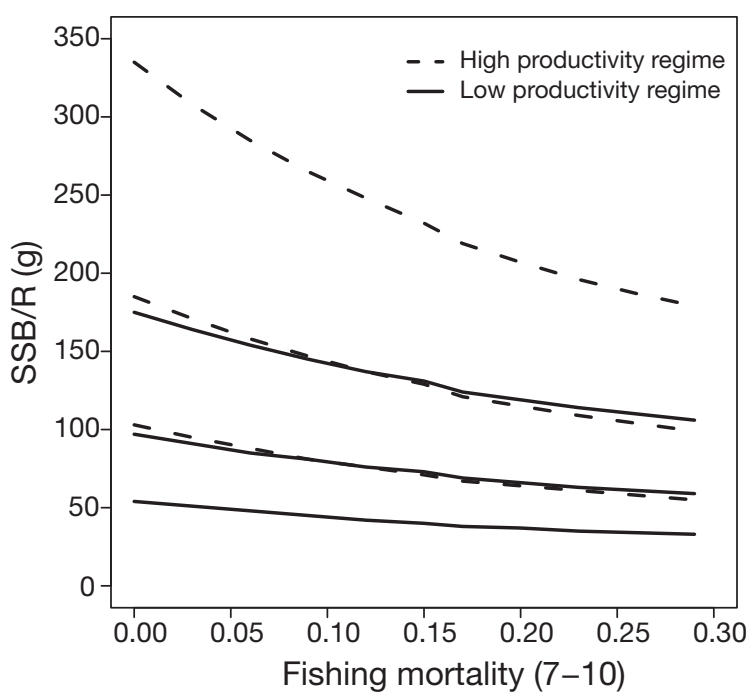

Fig. 10. Gadus morhua. Spawning stock biomass per recruit (SSB/R) as a function of fishing mortality for 3 different levels of harp seal predation and 2 distinct productivity regimes (see section 'Effects of seal predation vs. fishing on the reproductive potential' for details) 
mated during 2002 to 2006. Considering the harp seal predation mortality estimated in 2002 to 2006 and a low residual mortality (i.e. a high productivity regime), the SSB/R was estimated to be equal to $129 \mathrm{~g}$ (Fig. 10, intermediate dashed line curve). In this case and for a fishing mortality fixed at the level of 2000 to 2006, a decrease in the predation mortality rate from the mean value of $0.26 \mathrm{yr}^{-1}$ in 2000 to 2006 to a level around $0.13 \mathrm{yr}^{-1}$ observed in the mid-1980s would allow almost doubling the SSB/R (Fig. 10, upper dashed line curve). Changes in fishing mortality assuming constant predation mortality would be less beneficial to the SSB, a decrease from the fishing mortality rate of $0.15 \mathrm{yr}^{-1}$ in 2002-2006 to a low rate of $0.03 \mathrm{yr}^{-1}$ increasing the SSB from $129 \mathrm{~g}$ to $171 \mathrm{~g}$ per recruit. Considering a low productivity regime strongly decreased the SSB/R that was estimated to be $73 \mathrm{~g}$ in 2000 to 2006 , due to the higher residual mortality decreasing the probability of young cod to reach maturity (Fig. 10, intermediate solid line curve). In this case, the SSB/R for a predation mortality of $0.13 \mathrm{yr}^{-1}$ and constant fishing mortality would only be $131 \mathrm{~g}$ (Fig. 10, upper solid line curve). For the 2002 to 2006 predation mortality, a decrease in fishing mortality would slowly increase the SSB/R to a maximum of $97 \mathrm{~g}$ in the situation of a moratorium.

\section{DISCUSSION}

The SIMCAB statistical catch-at-age model was developed to assess the effects of predation by the northwest Atlantic harp seal population on NGSL cod by estimating the relative importance of different sources of mortality that affected the stock during a period of collapse and non-recovery. SIMCAB is a consistent modeling framework which combines the effects of fishing, predation mortality and environment (through the condition index) on cod population dynamics. SIMCAB showed that the increase in harp seal abundance during 1984-2006 resulted in an increase in predation mortality for cod age-groups targeted by seals. Despite the increasing importance of harp seal predation in cod mortality, the collapse of the NGSL cod stock appears mainly due to the combination of high fishing mortality rates and poor environmental conditions that affected the productivity of the population in the early to mid-1990s and led to the current state of recruitment overfishing. SIMCAB results also show, however, that current levels of predation mortality could increase stock rebuilding time by decreasing the probability of fish to reach maturity. Although cod condition has improved in recent years, the current lack of recovery of the NGSL cod seems due mainly to the very low spawner biomass, driven both by the fishery inherently targeting larger fish and increased harp seal predation. Within an ecosystem perspective, management scenarios based on a decline in seal population to promote stock rebuilding should however consider environmental conditions, prey availability for seals and other cod predators of the NGSL that all affect cod productivity and might give rise to unexpected outcomes with a decline in seal abundance.

\section{Multispecies modeling and functional response}

Separating the sources of mortality affecting animal populations is a major issue in ecology and has a long history in fisheries science (Andersen \& Ursin 1977). This is particularly important in the context of multispecies management as predator control has been proposed for some time as a beneficial tool for fisheries (Flaaten 1988, FRCC 1999). Multispecies models are useful tools to address the issues raised about the effects of marine mammals on fisheries (Yodzis 1998). In particular, predator-prey models have been used to evaluate the effects of fur seal Arctocephalus pusillus pusillus predation on hakes Merluccius capensis and Merluccius paradoxus in the Benguela system (Punt \& Butterworth 1995) and more recently the effects of northwest Atlantic grey seal Halichoerus grypus predation on cod population dynamics and causes of collapse and non recovery on the eastern Scotian shelf (ESS) have been explored (Mohn \& Bowen 1996, Fu et al. 2001, Trzcinski et al. 2006). In the Benguela system, modeling the biological interaction between cape fur seals and the cape hakes suggested that an initial reduction in seal numbers would be beneficial, but the resulting decrease in seal consumption would also result in increased predation by a less commercially important hake species $M$. capensis on the more commercially important hake $M$. paradoxus, resulting in little net benefit (Punt \& Butterworth 1995). Among northwest Atlantic grey seals, the first modeling approach included predation mortality explicitly in cohort analysis and showed that grey seals had little effect on the collapse of cod on the ESS (Mohn \& Bowen 1996). By contrast, more recent analyses suggested that increasing predation mortality since the 1990s could affect the survival of immature cod and contribute to the failure of the ESS and southern Gulf of St. Lawrence cod stocks to recover (Fu et al. 2001, Chouinard et al. 2005, Trzcinski et al. 2006).

The SIMCAB model is an age-structured population dynamics model structurally similar to the models used for grey seals on the ESS but it differs in several important points. A major difference with the models from Mohn \& Bowen (1996) and Fu et al. (2001) but addressed by Trzcinski et al. (2006) concerns the link- 
age between cod abundance and seal consumption through the functional feeding response. The form of the FR is a key issue in multispecies modeling, especially at low abundance, because it defines how predators impact their prey as a function of prey abundance (Yodzis 1994, Mackinson et al. 2003). Most multispecies models such as the Multi-Species Virtual Population Analysis (MSVPA; Magnússon 1995) are based on hyperbolic type 2 functional relationships between prey abundance and predation rates (for a review see Pláganyi 2007). These models assume constant ration formulations where per-capita consumption is set equal to the predator's required daily ration, consistent with the interpretation that feeding selectivities are independent of prey abundance. A sigmoidal functional response is however likely more appropriate when modeling generalist predators (Magnússon \& Pálsson 1991) and recent analyses based on field data tend to support a type 3 relationship (Middlemas et al. 2006, Kempf et al. 2008). In Ecopath with Ecosim models (Walters et al. 1997), the functional form of interactions is based on the 'foraging arena' concept that allows exploring alternative forms of functional response but biological and ecological justifications about this concept remain controversial (Pláganyi 2007).

In the present analysis, cod age-groups were considered distinct prey, consistently with the opportunistic behaviour of harp seals (Hammill \& Stenson 2000) and the size-based structure of marine food webs that regulates predation processes (e.g. Shin \& Cury 2004). The multi-age FR fitted to the data was a sigmoid shaped type 3 response, suggesting that the response of seals to changes in cod abundance might be complex and highly non-linear, due to predator preferences and potential for prey switching as a function of the relative abundance of prey types in the environment. A sigmoidal shape for the FR would be consistent with the available knowledge on the spatiotemporal and vertical distribution of cod that differs between cod age-groups, juvenile cod being generally found in shallower waters and closer to the shore than adult cod (e.g. Castonguay et al. 1999). Based on survey conducted on board the MV 'Gadus Atlantica' in winter from 1978 to 1994, young cod age-groups have been shown to occupy different depths and areas in the NGSL (DFO unpublished data), which could favor the emergence of a type 3 FR. Cod migration and distribution patterns might also change in time in relation to changes in environmental conditions affecting their habitat (Castonguay et al. 1999).

The sensitivity analysis showed that a type 2 FR would be less consistent with both the data and outputs from other predation models (Hammill \& Stenson 2004, Duplisea \& Hammill 2006). Although cod predation removals were of the same order of magnitude as those found with models based on linear assumptions about seal consumption (Hammill \& Stenson 2004, Duplisea \& Hammill 2006), the use of a FR led to different conclusions by accounting for changes in cod agegroups abundance in time. Our results are consistent with Middlemas et al. (2006) who provided empirical support for a type $3 \mathrm{FR}$ of seals to Atlantic salmon in an estuarine system in Scotland; however, in a multispecies or multi-age context, the interpretation of the FR type is not straightforward as the changes in alternative prey abundance influence the response of the predator to the availability of any prey (Smout \& Lindstrøm 2007). This will be important for harp seals who have been shown to show strong preference for pelagic species such as capelin Mallotus villosus but are neutrally selective towards cod (Lawson et al. 1998). Attempts to estimate statistical parameters of a FR have revealed the difficulty of relating microscale observations of stomach contents to the effective feeding responses of marine species at the macroscale (Pláganyi 2007). This is further complicated in the case of harp seal because biomass estimates of important alternative prey such as capelin, sandlance Ammodytes sp., Arctic cod Boreogadus saida and krill Euphausia sp. are not available for the NGSL. New data collection, experiments, and analyses such as conducted by Kempf et al. (2008) may help clarify harp seal sigmoidal feeding behaviour since modeling such nonlinear processes is key to explore the potential impact of management scenarios based on a decline in seal population.

\section{Cod population dynamics}

Despite major differences with the current method used to assess the cod stock status (e.g. no commercial data included in the analysis), SIMCAB estimates of cod abundance, fishing mortality, and SSB accorded with the last assessment of the northern Gulf cod (MPO 2007). Results were consistent with the collapse of the stock in the late 1980s and the current lack of recovery (MPO 2007). In the present analysis, cod abundance in the initial year 1984 was based on the numbers-at-age provided by VPA results, considering that the convergence property of this method would give reliable estimates of abundance in the past. Setting the initial cod numbers helped in the estimation of the parameters linking cod abundance to survey abundance indices, i.e. catchability and selectivity. Although a statistically 'optimal' solution was obtained through the fitting process, the information provided to the model was insufficient to distinguish between the level of residual mortality and magnitude of recruitment at age 1, i.e. there could be a correlation between the maximum recruit- 
ment $\left(R_{\max }\right)$ and the residual mortality parameters $(\alpha$ and $\beta$ ). Such a correlation could affect the absolute values of residual mortality at age 1 but would not modify the model results for the other cod age-groups for which information is provided through survey data.

A novel aspect of our cod population model is a stock-recruitment relationship based on egg production, which for cod is considered a better measure of the true reproductive potential of the stock than spawning biomass (Marshall et al. 2006). The high interannual variations in abundance indices for cod aged 1 to 2 yr included both natural survival variability of cod larvae and juveniles, and sampling noise associated with the research vessel gear that does not well select very small cod $(<15 \mathrm{~cm})$ predated by seals. In the context of trophic interactions where small fish form the bulk of the diet of many predators, collecting data on fish larvae and juveniles abundance appears as a key issue to explain the factors driving prerecruit survival and recruitment.

In addition, total egg production in our model was derived from a statistical model that related egg production to length-at-maturity and condition of mature females (Lambert 2008). Hence, recruitment in the model accounted for changes in growth of cod that could be density and/or temperature dependent (Swain et al. 2003), as well as changes in environment that could affect egg productivity through cod condition. Natural mortality other than harp seal predation was assumed to be age- and condition-dependent based on a comparative analysis between laboratory feeding experiments and wild cod collected in the Gulf of St. Lawrence in the 1990s (Lambert \& Dutil 1997a). The residual natural mortality term for old ages was consistent with temporal patterns estimated with virtual population analysis (Grégoire \& Fréchet 2005). Accounting for effects of condition on residual mortality led to a better fit of the model and suggested that the decline in the condition and energy reserves of cod during the 1990s may have lowered the productivity of the stock and contributed to its collapse (Lambert \& Dutil 1997a).

In contrast to the VPA, SIMCAB allows the separation of seal predation mortality from fishing mortality and other mortality through time and accounts for environmental influences on mortality and cod fecundity. Modeling the mechanistic processes involved in predation is a valuable alternative to the classic assumption of constant natural mortality rates to include some ecosystem components in stock assessment methods (e.g. Lindstrøm et al. 2002) and progressively move toward ecosystem-based fishery management (Pikitch et al. 2004). This seems particularly critical for conducting stock projections to evaluate the expected effects of fishery management rules (e.g. Hollowed et al. 2000) in a context where predation is suspected to delay the NGSL cod stock recovery.

\section{Cod recovery within an ecosystem perspective}

The impact of changes in predation and fishing mortality on the SSB/R was assessed for different values of residual natural mortality assumed here to represent different environmental conditions. Diagnostics about a decline in seal predation were then shown to be dependent on the productivity of the stock related to the environment (Dutil et al. 2003). Residual mortality affecting young cod was shown to be more important than harp seal predation but not explicitly modelled in the present analysis. Predation mortality has been shown to be the dominant source of mortality for small $\operatorname{cod}(\leq 35 \mathrm{~cm})$ in the $1990 \mathrm{~s}$ and $2000 \mathrm{~s}$, representing about $95 \%$ of total mortality (Savenkoff et al. 2006). In the NGSL, small cod have been shown to be preyed upon by large cod through cannibalism, other large demersals (e.g. white hake Urophycis tenuis), grey seals and boreal cetaceans including mysticetes such as minke whale Balaenoptera acutorostrata and odontocetes such as white-beaked dolphins Lagenorhynchus albirostris (Morissette et al. 2006, Savenkoff et al. $2004,2006,2007)$. While cannibalism decreased in the last decades due to the decline in adult stock biomass, it still represented an important component of mortality for small cod in the early 2000s (Savenkoff et al. 2007). A high proportion of the total mortality of cod aged 3 to 10 yr was also not explained by harp seal predation or fishing and attributed to residual mortality. This residual mortality includes both a predation mortality component due to large cod predators such as grey seals and another mortality component that could involve starvation, disease, and parasites (Savenkoff et al. 2004, 2006). In SIMCAB, mortality linked to these latter factors was related to cod condition through the asymptote of residual mortality, assuming that fish in bad condition would have little energy reserves to survive over the winter months or critical stages of their life cycle (Lambert \& Dutil 1997a, Dutil et al. 1999).

Based on the large database of cod stomachs collected by Fisheries and Oceans Canada during numerous research and commercial fishing-vessel surveys since the mid-1980s, modelling explicitly cannibalism within SIMCAB could help separating the components of residual mortality for small cod. Following the oneway interaction modelled between harp seal and cod, predation by other species than harp seals such as grey seals could also be included in the model if suitable data are available. The use of ecosystem models such as mass-balanced and end-to-end models (Travers et al. 2007) in complement to SIMCAB would allow to 
represent the full complexity of the food web, to identify the major factors affecting cod mortality, to include bottom-up effects of prey availability on production and mortality, and eventually to compare simulation outputs for assessing the robustness of the results.

Long-term projections based on the SSB/R analysis did not consider issues of recruitment in a context where the low reproductive potential of the stock associated with a low productivity are major factors explaining its lack of recovery (Dutil et al. 2003, Shelton et al. 2006). Projections performed with SIMCAB to estimate recovery time should also account for the effects of condition on recruitment (Lambert et al. 2000, Marteinsdottir \& Begg 2002) and growth (Dutil et al. 1999) that would also modify the response of the cod population to the implementation of management rules based on a decline in seal population. Considering alternative projection scenarios based on different harvest control rules for the commercial cod fishery and different environmental regimes is important to determine the utility of managing seals to increase the recovery rate of the NGSL cod population.

\section{CONCLUSION}

The main objectives of this study were to examine the relative impacts of fishing, environmental conditions and seal predation on the decline and recovery of the NGSL cod population within a consistent modeling framework. Within this framework harp seals could play an important role in the recovery of NGSL cod. This framework lends itself to adding additional components which might result in different conclusions. For example, harp seals are generalist predators and their impact will be affected by the availability of alternative prey. Elsewhere it has been shown that incorporating even only a few other prey alternatives may result in different and unexpected outcomes (Punt \& Butterworth 1995, Morissette et al. 2006, Matthiopoulos et al. 2007). Therefore, although harp seals may have an important impact on recovery of NGSL cod population, efforts to manage seals with this objective in mind may not achieve the expected outcomes because of other components within the NGSL marine ecosystem.

Acknowledgements. We are grateful to P. Carter, S. Turgeon, D. McKinnon, W. Penney, B. Stockwood, D. Wakeham, and $\mathrm{H}$. Bourdages for providing data on seal diet and cod abundance indices. K. Trzcinski and B. Mohn made useful suggestions on the modeling approach, M.-N. Bourassa and J.F. Gosselin helped in map drawing. The work benefited from discussions with A. Fréchet, P. Schwab, J. Gautier, and M. Koen-Alonso. Comments by 3 anonymous referees greatly helped to improve and to clarify the manuscript. This work was financed by DFO's species at risk funding program (SARCEP).

\section{LITERATURE CITED}

Akaike H (1974) A new look at the statistical model identification. IEEE Trans Automat Contr 19:716-723

Andersen KP, Ursin E (1977) A multispecies extension to the Beverton and Holt theory of fishing, with accounts of phosphorus circulation and primary production. Medd Dan Fisk-Havunders NS Vol 7:319-435

Beverton RJH, Holt SJ (1957) On the dynamics of exploited fish populations. Fisheries investigations series 2. UK Ministry of Agriculture, Fisheries and Food, London

Bourdages H, Archambault D, Morin B, Fréchet A, Savard L, Grégoire F, Bérubé M (2003) Preliminary results from the groundfish and shrimp multidisciplinary survey from $\mathrm{Au}-$ gust 2003 in the northern Gulf of St. Lawrence. DFO Can Sci Advis Sec Res Doc 2003/078. Department of Fisheries and Oceans Canada, Ottawa

Bourdages H, Savard L, Archambault D, Valois S (2007) Résultats de l'expérience de la pêche comparative d'août 2004 et 2005 dans le nord du golfe Saint-Laurent, entre le NGCC Alfred Needler et le NGCC Teleost. Rapp tech can sci halieut aquat, 2750, Ministère des Pêches et des Océans, Ottawa

Bundy A (2001) Fishing on ecosystems: the interplay of fishing and predation in Newfoundland-Labrador. Can J Fish Aquat Sci 58:1153-1157

> Castonguay M, Rollet C, Fréchet A, Gagnon P, Gilbert D, Brêthes JC (1999) Distribution changes of Atlantic cod (Gadus morhua L.) in the northern Gulf of St Lawrence in relation to an oceanic cooling. ICES J Mar Sci 56:333-344

Chassot E, Caskenette A, Duplisea DE, Hammill MO, Bourdages H, Lambert Y, Stenson GB (2007) A model of predation by harp seals (Phoca groenlandica) on the northern Gulf of St. Lawrence stock of Atlantic cod (Gadus morhua). DFO Can Sci Advis Sec Res Doc 2007/066. Department of Fisheries and Oceans, Ottawa

Chouinard GA, Swain DP, Hammill MO, Poirier GA (2005) Covariation between grey seal (Halichoerus grypus) abundance and natural mortality of cod (Gadus morhua) in the southern Gulf of St. Lawrence. Can J Fish Aquat Sci 62:1991-2000

Stenson GB, Hammill MO, Lawson JW (1997) Predation by harp seals in Atlantic Canada: preliminary consumption estimates for Arctic cod, capelin and Atlantic cod. J Northw Atl Fish Sci 22:137-154

DFO (2003) Proceedings of the zonal assessment meeting Atlantic cod. DFO Can Sci Advis Sec Proceed Ser 2003/ 021

Du J (2002) Combined algorithms for constrained estimation of finite mixture distributions with grouped data and conditional data. MS thesis McMaster University

Duplisea DE, Hammill MO (2006) An approach to modelling the influence of harp seal (Phoca groenlandica) predation on decline and recovery of the Northern Gulf of St. Lawrence cod (Gadus morhua). International Council for the Exploration of the Sea, ICES CM 2006/L: 02

> Dutil JD, Lambert Y (2000) Natural mortality from poor condition in Atlantic cod (Gadus morhua). Can J Fish Aquat Sci 57:826-836

Dutil JD, Castonguay M, Gilbert D, Gascon D (1999) Growth, condition, and environmental relationships in Atlantic cod (Gadus morhua) in the northern Gulf of St. Lawrence and implications for management strategies in the Northwest Atlantic. Can J Fish Aquat Sci 56:1818-1831

Dutil JD, Gauthier J, Lambert Y, Fréchet A, Chabot D (2003) Cod stocks rebuilding and fish bioenergetics: low productivity hypothesis. DFO Can Sci Advis Sec Res Doc 2003/060. Department of Fisheries and Oceans, Ottawa 
Efron B, Tibshirani RJ (1998). An introduction to the Bootstrap. Chapman \& Hall, London

Flaaten O (1988) The economics of multispecies harvesting. Springer Verlag, Berlin

Fournier D, Archibald CP (1982) A general theory for analyzing catch at age data. Can J Fish Aquat Sci 39: 1195-1207

FRCC (1999) Conservation requirements for the Gulf of St. Lawrence groundfish stocks and cod stocks in divisions 2GH and 3Ps and science priorities. Report to the Minister of Fisheries and Oceans. FRCC.99.R.1, April 1999 Fisheries Resource Conservation Council, Ottawa

Fréchet A, Gauthier J, Schwab P, Bourdages H and others (2003a) The status of cod in the Northern Gulf of St. Lawrence (3Pn, 4RS) in 2002. DFO Can Sci Advis Sec Res Doc 2003/065. Department of Fisheries and Oceans, Ottawa

Fréchet A, Butler R, Hussey E, Kennedy J, Rose G (2003b) Quality at landing in relation to gears used in the 3Pn, 4R cod fishery, 2000-2002. DFO Can Sci Advis Sec Res Doc 2003/066. Ministère des Pêches et des Océans, Ottawa

Fréchet A, Gauthier J, Schwab P, Bourdages H and others (2007) The status of cod in the Northern Gulf of St. Lawrence (3Pn, 4RS) in 2006. DFO Can Sci Advis Sec Res Doc 2007/068. Department of Fisheries and Oceans, Ottawa

Fu C, Mohn R, Fanning LP (2001) Why the Atlantic cod (Gadus morhua) stock off eastern Nova Scotia has not recovered. Can J Fish Aquat Sci 58:1613-1623

Fulton T (1902) Rate of growth of seas fishes. Sci Invest Fish Div of Scotland 20:1035-1039

Grégoire F, Fréchet A (2005) Calculation of northern Gulf of St. Lawrence cod (Gadus morhua) natural mortality for the 1990 to 2004 period. DFO Can Sci Advis Sec Res Doc 2005/019. Department of Fisheries and Oceans, Ottawa

Hammill MO, Stenson GB (2000) Estimated prey consumption by harp seals (Phoca groenlandica), hooded seals (Cystophora cristata), grey seals (Halichoerus grypus) and harbour seals (Phoca vitulina) in Atlantic Canada. J Northwest Atl Fish Sci 26:1-23

Hammill MO, Stenson GB (2004) Estimated consumption of Atlantic cod (Gadus morhua) by harp seals (Phoca groenlandica), in NAFO Zone 4RS. DFO Can Sci Advis Sec Res Doc 2004/093. Department of Fisheries and Oceans, Ottawa

Hammill MO, Stenson GB (2005) Abundance of Northwest Atlantic harp seals (1960-2005). DFO Can Sci Advis Sec Res Doc 2005/090. Department of Fisheries and Oceans, Ottawa

> Hammill MO, Stenson GB, Myers RA, Stobo WT (1998) Pup production and population trends of the grey seal (Halichoerus grypus) in the Gulf of St. Lawrence. Can J Fish Aquat Sci 55:423-430

Hammond TR, Trenkel VM (2005) Censored catch data in fisheries stock assessment. ICES J Mar Sci 62:1118-1130

> Hollowed AB, Ianelli JN, Livingston PA (2000) Including predation mortality in stock assessments: a case study for Gulf of Alaska walleye Pollock. ICES J Mar Sci 57:279-293

Hutchings JA (1996) Spatial and temporal variation in the density of northern cod and a review of hypotheses for the stock's collapse. Can J Fish Aquat Sci 53:943-962

Kempf A, Floeter J, Temming A (2008) Predator-prey overlap induced Holling type III functional response: an example from the North Sea fish assemblage. Mar Ecol Prog Ser 367:295-308

Koen-Alonso M (2006) A process-oriented approach to the multispecies functional response. In: Rooney N, McCann KS, Noaks DLG (eds): From energetics to ecosystems: The dynamics and structure of ecological systems, Springer, Dordrecht, p 1-36
Lambert Y (2008) Why should we closely monitor fecundity in marine fish populations? J Northwest Atl Fish Sci 41: 93-106

> Lambert Y, Dutil JD (1997a) Condition and energy reserves of Atlantic cod (Gadus morhua) during the collapse of the northern Gulf of St. Lawrence stock. Can J Fish Aquat Sci 54:2388-2400

Lambert Y, Dutil JD (1997b) Can simple condition indices be used to monitor and quantify seasonal changes in the energy reserves of Atlantic cod (Gadus morhua)? Can J Fish Aquat Sci 54:104-112

> Lambert Y, Dutil JD (2000) Energetic consequences of reproduction in Atlantic cod (Gadus morhua) in relation to spawning level of somatic energy reserves. Can J Fish Aquat Sci 57:815-825

Lambert Y, Dutil JD, Ouellet P (2000) Nutritional condition and reproductive success in wild fish populations. In: Norberg B, Kjesbu OS, Taranger GL, Andersson E, Stefansson SO (eds) Proc 6th Int Symp Rep Phys Fish. Inst Mar Res \& Univ Bergen, Bergen, Norway, p 77-84

Lawless JF (2003) Statistical models and methods for lifetime data, 2nd edition. John Wiley \& Sons, Hoboken

> Lawson JW, Anderson JT, Dalley EL, Stenson GB (1998) Selective foraging by harp seals Phoca groenlandica in nearshore and offshore waters of Newfoundland, 1993 and 1994. Mar Ecol Prog Ser 163:1-10

> Lindstrøm U, Harbitz A, Haug T, Nilssen KT (1998) Do harp seals Phoca groenlandica exhibit particular prey preferences? ICES J Mar Sci 55:941-953

Lindstrøm U, Haug T, Røttingen I (2002) Predation on herring, Clupea harengus, by minke whales, Balaenoptera acutorostrata, in the Barents Sea ICES. J Mar Sci 59:58-70

Mackinson S, Blanchard JL, Pinnegar JK, Scott R (2003) Consequences of alternative functional responses in models exploring whale-fishery interactions. Mar Mamm Sci 19: 661-681

Magnússon KG (1995) An overview of the multispecies VPAtheory and applications. Rev Fish Biol Fish 5:195-212

Magnússon KG, Pálsson OK (1991) Predator-prey interactions of cod and capelin in Icelandic waters. ICES Mar Sci Symp 193:153-170

Marshall CT, Needle CL, Thorsen A, Kjesbu OS, Yaragina NA (2006) Systematic bias in estimates of reproductive potential of an Atlantic cod (Gadus morhua) stock: implications for stock-recruit theory and management. Can J Fish Aquat Sci 63:980-994

Marteinsdottir G, Begg GA (2002) Essential relationships incorporating the influence of age, size and condition on variables required for estimation of reproductive potential in Atlantic cod Gadus morhua. Mar Ecol Prog Ser 235: $235-256$

Matthiopoulos J, Graham K, Smout S, Asseburg C and others (2007) Sensitivity to assumptions in models of generalist predation on a cyclic prey. Ecology 88:2576-2586

McLaren I, Brault S, Harwood J, Vardy D (2001) Report of the eminent panel on seal management. Department of Fisheries and Oceans, Ottawa, Canada

Middlemas SJ, Barton TR, Armstrong JD, Thompson PM (2006) Function and aggregative response of harbour seals to changes in salmonid abundance. Proc R Soc Lond B Biol Sci 273:193-198

> Mohn R, Bowen WD (1996) Grey seal predation on the eastern Scotian Shelf: modelling the impact on Atlantic cod. Can J Fish Aquat Sci 53:2722-2738

Morissette L, Hammill MO, Savenkoff C (2006) The trophic role of marine mammals in the northern Gulf of St. Lawrence. Mar Mam Sci 22(1):74-103 
MPO (2007) Évaluation du stock de morue du nord du golfe du Saint-Laurent (3Pn, 4RS) en 2006. Secrétariat canadien de consultation scientifique, Avis scientifique 2006/010. Available at: www.dfo-mpo.gc.ca/csas/Csas/etat/2006/ SAR-AS2006_010_F.pdf

Myers RA, Cadigan NG (1995) Statistical analysis of catch-atage data with correlated errors. Can J Fish Aquat Sci 52: 1265-1273

Myers RA, Barrowman NJ, Hoenig JM, Qu Z (1996) The collapse of cod in eastern Canada: the evidence from tagging data. ICES J Mar Sci 53:629-640

Myers RA, Hutchings JA, Barrowman NJ (1997) Why do fish stocks collapse? The example of cod in Atlantic Canada. Ecol Appl 7:91-106

Pikitch EK, Santora C, Babcock EA, Bakun A and others (2004) Ecosystem-based fishery management. Science 305:346-347

Plaganyi, E (2007) Models for an ecosystem approach to fisheries. FAO Fisheries Technical Paper. No 477. FAO, Rome

Pope JG (1972) An investigation of the accuracy of Virtual Population Analysis using cohort analysis. Int Comm Northwest Atl Fish Res Bull 9:65-74

Punt AE, Butterworth DS (1995) The effects of future consumption by the Cape fur seal on catches and catch rates of the Cape hakes. 4. Modelling the biological interaction between Cape fur seals Arctocephalus pusillus pusillus and the Cape hakes Merluccius capensis and M. paradoxus. S Afr J Mar Sci 16:255-285

Quinn TJ II, Deriso RB (1999) Quantitative fishery dynamics. Oxford University Press, New York

R Development Core Team (2008) R: A language and environment for statistical computing. R Foundation for Statistical Computing, Vienna. Available at: http://cran.r-project. org/doc/manuals/refman.pdf

Rätz HJ, Lloret J (2003) Variation in fish condition between Atlantic cod (Gadus morhua) stocks, the effect on their productivity and management implications. Fish Res 60: 369-380

Rice JC, Shelton PA, Rivard D, Chouinard GA, Fréchet A (2003) Recovering Canadian Atlantic cod stocks: the shape of things to come? International Council for the Exploration of the Seas, ICES CM 2003/U:06

Savenkoff C, Castonguay M, Vézina AF, Despatie SP, Chabot D, Morissette L, Hammill MO (2004) Inverse modelling of trophic flows through an entire ecosystem: the northern Gulf of St. Lawrence in the mid-1980s. Can J Fish Aquat Sci 61:2194-2214

Savenkoff C, Castonguay M, Chabot D, Fréchet A, Hammill MO, Morissette L (2006) Main prey and predators and estimates of mortality of Atlantic cod (Gadus morhua) in the northern Gulf of St. Lawrence during the mid-1980s, mid-1990s, and early 2000s. Can Tech Rep Fish Aquat Sci 2666. Department of Fisheries and Oceans, Ottawa

Savenkoff C, Castonguay M, Chabot D, Hammill MO, Bourdages H, Morissette L (2007) Changes in the northern Gulf of St. Lawrence ecosystem estimated by inverse modelling: evidence of a fishery-induced regime shift? Estuar Coast Shelf Sci 73:711-724

Editorial responsibility: Jake Rice,

Ottawa, Ontario, Canada
Shelton PA, Healey BP (1999) Should depensation be dismissed as a possible explanation for the lack of recovery of the northern cod (Gadus morhua) stock? Can J Fish Aquat Sci 56:1521-1524

Shelton PA, Sinclair AF, Chouinard GA, Mohn R, Duplisea DE (2006) Fishing under low productivity conditions is further delaying recovery of Northwest Atlantic cod (Gadus morhua). Can J Fish Aquat Sci 63:235-238

Shin YJ, Cury P (2004) Using an individual-based model of fish assemblages to study the response of size spectra to changes in fishing. Can J Fish Aquat Sci 61:414-431

Smout S, Lindstrøm U (2007) Multispecies functional response of the minke whale Balaenoptera acutorostrata based on small-scale foraging studies. Mar Ecol Prog Ser 341: $277-291$

Stenson GB, Hammill MO (2004) Quantifying uncertainty in estimates of Atlantic cod (Gadus morhua) consumption by harp seals (Phoca groenlandica). DFO Can Sci Advis Sec Res Doc 2004/089. Department of Fisheries and Oceans, Ottawa

Stenson GB, Hammill MO, Lawson JW (1997) Predation by harp seals in Atlantic Canada: preliminary consumption estimates for Arctic cod, capelin and Atlantic cod. J Northw Atl Fish Sci 22:137-154

Stenson GB, Hammill MO, Kingsley MCS, Sjare B, Warren WG, Myers RA (2002) Is there evidence of increased pup production in northwest Atlantic harp seals, Pagophilus groenlandicus? ICES J Mar Sci 59:81-92

> Stenson GB, Rivest LP, Hammill MO, Gosselin JF, Sjare B (2003) Estimating pup production of harp seals, Pagophilus groenlandicus, in the Northwest Atlantic. Mar Mamm Sci 19:141-160

Swain DP, Sinclair AF, Castonguay M, Chouinard GA, Drinkwater KF, Fanning LP, Clark DS (2003) Densityversus temperature-dependent growth of Atlantic cod (Gadus morhua) in the Gulf of St. Lawrence and on the Scotian Shelf. Fish Res 59:327-341

- Travers M, Shin Y, Jennings S, Cury P (2007) Towards endto-end models for investigating the effects of climate and fishing in marine ecosystems. Prog Oceanogr 75: 751-770

Trzcinski MK, Mohn R, Bowen WD (2006) Continued decline of an Atlantic cod population: how important is gray seal predation? Ecol Appl 16:2276-2292

> Walters CJ, Christensen V, Pauly D (1997) Structuring dynamic models of exploited ecosystems from trophic massbalance assessments. Rev Fish Biol Fish 7:139-172

> Wathne JA, Haug T, Lydersen C (2000) Prey preference and niche overlap of ringed seals Phoca hispida and harp seals P. groenlandica in the Barents Sea. Mar Ecol Prog Ser 194: 233-239

> Yodzis P (1994) Predator-prey theory and management of multispecies fisheries. Ecol Appl 4:51-58

> Yodzis P (1998) Local trophodynamics and interaction of marine mammals and fisheries in the Benguela ecosystem. J Anim Ecol 67:635-658

Submitted: June 20, 2008; Accepted: December 12, 2008

Proofs received from author(s): March 19, 2009 